\title{
Numerical simulation on dynamic behavior of reinforced concrete beam with initial cracks subjected to air blast loading
}

\author{
Yandong Qu *, Xin Li, Xiangqing Kong, Wenjiao Zhang, Xuezhi Wang \\ School of Civil and Architecture Engineering, Liaoning University of Technology, Jinzhou 121001, China
}

Corresponding Author: Tel. +86 4164198727

*E-mail address: quyandong@lnut.edu.cn (Y.D. Qu)

\begin{abstract}
Reinforced concrete (RC) structural members subjected to blast loading behave differently as compared to the same subjected to quasi-static loading. Numerical studies are conducted to study the influence of weights and positions of explosive charges, locations, widths and depths of initial cracks, and longitudinal reinforcement ratios
\end{abstract} on the dynamic behavior of simply supported RC beam with initial cracks (pre-cracked RC beam) under air blast loading. Results show that, compared with the perfect beams, the pre-cracked RC beams present themselves with an increase in the maximum deflection of mid-span, the maximum vertical velocity of mid-span node, effective stresses of concrete in compressive zone of the pre-cracked RC beam, and axial stresses of longitudinal reinforcement in tensile zone of the pre-cracked RC beam. Due to stress concentration of pre-cracked sections under air blast loading, the presence of initial cracks at the mid-span (or the end) of the pre-cracked RC beam could cause the failure of the pre-cracked RC beam prematurely at the cracked sections and where the blast loading begin to be loaded. Moreover, a crack on the surface of compression zone of the pre-cracked RC beam has a larger influence than that on the surface of tensile zone. The damage generated by blast loading effects is limited to a local area, and the dynamic behavior of the pre-cracked RC beam is not sensitive to the width and depth of initial cracks to some extent.

Keywords: Reinforced concrete beam; Blast loading; Dynamic behavior; Failure mode; Pre-cracked beam

\section{Introduction}

Over recent decades, frequent occurrence of various terrorist attacks, industrial accidents has generated concern over a general vulnerability to blast seen in many conventionally designed structures, with localized blast 
damage causing global collapse in some cases [1-3]. Analysis of dynamic performances of reinforced concrete (RC) structures against air blast loading is a complex issue because the short duration of blast loading often exhibits spatial and time variations, which result in a varying strain rate for concrete material as well as steel reinforcement [4-6].

As one of the main bearing components of RC structures commonly used in protective design against potential blast loading conditions, analysis of dynamic behavior of RC beams has important significance in the design of anti-explosion structures. Current analysis methods for RC components subjected to blast loading consist of two major approaches: experimental and numerical studies. Many experimental studies are not feasible because the preparations and measurements in full-scale field experiments are complex and expensive, however. Fortunately, there are some remarkable exceptions. For instance, Zhang et al. [7] found that the decrease of the scaled distance could lead to the increase of spalling area according to the damage characters of RC beams under close-in blast loading. Ohtsu et al. [8] through experiment and analysis studied the dynamic failure of fiber-reinforced concrete slabs under blast loading. Wang et al. [9] investigated the explosion resistance of a one-way square RC slab subjected to closed-in blast loading and two major damage levels (moderate spallation, spallation with a few cracks) were identified in the tests. Magnusson and Hallgren [10-11] studied many RC beams made of normal or high strength concrete, with or without steel fibers, subjected to air blast loading. Chen and Yang [12] experimentally investigated the explosion-resistant capabilities of fifteen RC beams of three groups strengthened with carbon fiber reinforced polymer (CFRP) sheets under blast loading. Ohtsu et al. [13] experimentally and analytically investigated the dynamic failure of fibre-reinforced concrete (FRC) slabs, and it was observed that the averaged diameters and the volumes of the spall failure remarkably decreased with the increase in the flexural toughness of FRC concrete. Recently, Wang et al. [14] conducted experimental study on explosion resistance of a one-way square RC slab under closed-in blast loading. In order to evaluate the effectiveness of a numerical model to replicate the experimental damages of RC columns, Ambrosini et al. [15] experimentally investigated the damages of RC columns subjected to close-in blast loading. Numerical analysis also takes a very important role in studying the dynamic behaviors of RC structures under blast loading [16]. Zhou et al. [17] predicted the responses of high-strength steel fiber RC slabs and ordinary RC slabs under blast loading by proposing a dynamic plastic damage model for concrete material. Later, Zhou and Hao [18] modeled and analyzed the damage and fragmentation of concrete slab under contact detonation. Li and his coworkers [19] conducted experimental study on the dynamic performance of ultra-high-performance-concrete (UHPC) slab under contact charge explosion.

Mazurkiewicz et al. [20] developed the multistage numerical analyses procedure for a load carrying capacity 
assessment of a blast loaded I-column. Xu et al. [21] experimentally and analytically investigated the behavior of ultra high performance fibre reinforced concrete (UHPFRC) columns under blast loading. Mao et al. [22] investigated the dynamic performance of UHPFRC under blast loading using the explicit non-linear finite element program, LS-DYNA. Qu et al. [23] studied the influence of bearing types on the damage modes of RC beam under air blast loads by numerical simulation. General behavior of concrete plates subjected to air blast loading was investigated by $\mathrm{Xu}$ and $\mathrm{Lu}$ [24], they focused on the spall damage and proposed empirical spallation criteria considering the response of three-dimensional concrete. Utilizing Timoshenko Beam Theory, Dragos and Wu [25] investigated the interaction between direct shear and flexural responses for blast loaded one-way RC slabs using a finite element model.

It is noticed from the above literature review, most of the previous studies are limited to uniform and perfect structures. However, cracks, notches or defects may be contained on the cross-sections of real structures. Defects influence in a negative way the service life of structures. Thus, the failure features of simple cracked (imperfect) structures have been a focal point of research. For instance, Hudson and Darwin [26] used explosives to damage several RC beams and strengthened some of them with CFRP. They examined if the repaired beams exhibited enhanced flexural capacity with respect to the unrepaired ones. Chondros and Dimarogonas [27] investigated an aluminum cantilever beam with a crack based on a number of experiments and concluded that both experiments and the mathematical formulae shared the same conclusion. Paik et al. [28] studied the behaviors of cracked plates and estimated the ultimate strength of cracked plates under compression and tension by proposing theoretical models. Alinia et al. [29] investigated the effect of relative crack length on buckling capacity of shear panels using the finite element method. Wu and Davies [30] developed a theoretical method to predict the loading capacity of a cracked FRP RC flexural beam.

In conclusion, most of the previous studies are limited to uniform and perfect RC structures under blast loading and the studies of pre-cracked RC beams are mainly focused on considering being subjected to static loading. Only limited research has been developed to study dynamic behavior of simply supported RC beams with initial cracks (pre-cracked RC beam) subjected to blast loading. Cracks influence in a negative way the service life of structures. The available methods for predicting the damage of RC beams subjected to blast loading might not be applicable to predict the damage of pre-cracked RC beams. In the present study, a numerical investigation is carried out to study the dynamic behavior of pre-cracked RC beam under blast loading. Finite element model is verified first through simulation of a previous experimental test reported in the literature. Then, parametric studies are performed to examine the influence of weights and positions of explosive charges, locations, widths and depths of initial cracks, 
and longitudinal reinforcement ratios on the dynamic behavior of the pre-cracked RC beam under air blast loading.

\section{Verification of numerical model}

Finite element analysis of RC beam was carried out using the non-linear transient dynamic finite element code LS-DYNA. In order to validate the accuracy and reliability of simulated results, the RC beam specimen numbered for B2-1 from the experiment conducted by Zhang et al. [7] is studied by numerical simulation. The test setup is shown in Fig. 1. Longitudinal reinforcements consist of four steel bars of Ф6-HPB235. While Ф6-HPB235 bars are used for transverse reinforcements. The cube-like TNT charge of $0.36 \mathrm{~kg}$ is detonated at a standoff distance of 0.4 $\mathrm{m}$ above the mid-span top of the tested beam. The standoff distance is measured from the underside of the TNT charge to the top surface of the tested beam. The uniaxial compressive strength of concrete is $40 \mathrm{MPa}$. The yield strength and ultimate strength of reinforcement steels Ф6-HPB235 are $395 \mathrm{MPa}$ and $501 \mathrm{MPa}$, respectively. More detailed information of the tested beam can be found in Ref. [7].

\subsection{Numerical model}

\subsubsection{Material model}

In this study, the material model named *MAT_JOHNSON_HOLMQUIST_CONCRETE (MAT_111) (HJC) is used to model the behavior of concrete material. HJC model can be used to simulate the concrete subjected to large strains, high strain rates, and high pressures [31]. The equivalent strength is expressed as a function of the pressure, strain rate, and damage. The pressure is expressed as a function of the volumetric strain and includes the effect of permanent crushing. The damage is accumulated as a function of the plastic volumetric strain, equivalent plastic strain and pressure [31]. A more detailed description of this model can be found in the paper by Holmquist, Johnson, and Cook [32]. The material parameters of ordinary concrete [7, 33] are shown in Table 1. Previous studies have demonstrated the reliability of the material model in predicting response of RC structure subjected to blast loading $[32,34,35,36]$. For steel reinforcement, the material model named *MAT_PLASTIC_KINEMATIC (MAT_003) is used. Isotropic and kinematic hardening plasticity with the option of including rate effects are modeled in the material model. The model is available for solid, shell, and beam (Hughes-Liu) elements. The material parameters of steel reinforcement are shown in Table $2[37,38]$. The material model named *MAT_RIGID 
(MAT_020) is used to model the support steel plate. Realistic values of Poisson's ratio and Young's modulus of steel material are used to define the rigid material to avoid numerical problems in contact.

\subsubsection{Strain rate effect}

As strain rate sensitive materials, the strain rate effects of concrete and steel are taken into consideration. Dynamic increase factor (DIF) for the tensile strength of steel is defined according to Ref. [39], and that for the tensile strength of concrete is defined according to Ref. [40], and that for compressive strength of concrete is defined according to the empirical function provided by CEB-FIP Model Code 1990 [41].

For steel reinforcement:

$$
D I F=\left(\frac{\dot{\varepsilon}}{10^{-4}}\right)^{\alpha}
$$

where for the yield strength, $\alpha=\alpha_{f y}=0.074-0.04 f_{y} / 60$; and for the ultimate stress, $\alpha=\alpha_{f u}=0.019-0.009 f_{y} / 60$.

For tensile strength of concrete:

$$
D I F=\frac{f_{t}}{f_{t s}}= \begin{cases}\left(\frac{\dot{\varepsilon}}{\dot{\varepsilon}_{s}}\right)^{\delta} & \text { for } \varepsilon \leq 1 s^{-1} \\ \beta\left(\frac{\dot{\varepsilon}}{\dot{\varepsilon}_{s}}\right)^{1 / 3} & \text { for } \varepsilon>1 s^{-1}\end{cases}
$$

where $f_{t s}$ is the static tensile strength at $\dot{\varepsilon}_{s} ; f_{t}$ is the dynamic tensile strength at $\dot{\varepsilon} ; \dot{\varepsilon}_{s}$ is the static strain rate $10^{-6}$ $\mathrm{s}^{-1} ; \dot{\varepsilon}$ is the strain rate in the range of $10^{-6}$ to $160 \mathrm{~s}^{-1} ; \log \beta=6 \delta-2 ; \delta=1 /\left(1+8 f_{c s} / f_{c o}\right) ; f_{c o}=10 \mathrm{MPa}$.

For compressive strength of concrete:

$$
D I F=\frac{f_{c}}{f_{c s}}= \begin{cases}\left(\frac{\dot{\varepsilon}}{\dot{\varepsilon}_{s}}\right)^{1.026 \alpha} & \text { for } \varepsilon \leq 30 s^{-1} \\ \gamma_{s}\left(\frac{\dot{\varepsilon}}{\dot{\varepsilon}_{s}}\right)^{1 / 3} & \text { for } \varepsilon>30 s^{-1}\end{cases}
$$

where $f_{c s}$ is the static compressive strength of concrete at $\dot{\varepsilon}_{s} ; f_{c}$ is the dynamic compressive strength of concrete at $\dot{\varepsilon} ; \dot{\varepsilon}_{s}$ is the static strain rate $30 \times 10^{-6} \mathrm{~s}^{-1} ; \dot{\varepsilon}$ is the strain rate in the range of $30 \times 10^{-6}$ to $300 \mathrm{~s}^{-1} ; \gamma$ is from $\log \gamma_{\mathrm{s}}=$ $6.156 \alpha-2 ; \alpha$ is the coefficient given by $\alpha=1 /\left(5+9 f_{c s} / f_{c o}\right)$; and $f_{c o}=10 \mathrm{MPa}$.

It was mentioned in the CEB-FIP Model Code [41] that Eq. (3) should be applied when the strain rate fell in the range between $30 \times 10^{-6} \mathrm{~s}^{-1}$ and $300 \mathrm{~s}^{-1}$. From the study of Tedesco and his coworkers [41], the DIF values are in range of $\sim 1.5$ (almost constant for strain rate in range from $10^{-4}$ to $10^{-2} \mathrm{~s}^{-1}$ ) and 1.7 1.75 for concrete in 
compression and tension respectively for the present simulation. It is worth pointing out that a large number of empirical DIF relations have been proposed to model concrete material strength increment at high strain rates [42-45]. It is commonly acknowledged that the induced structural effects such as lateral inertia contentment effect are inevitable in high-speed impact tests. Some recent studies investigated the contributions of lateral inertia and friction confinement effects on DIF of concrete materials in laboratory tests, and proposed relations to remove these influences to obtain the true DIF for concrete materials [44, 46-47]. The three DIF relations (CEB-DIF, New DIF, and No DIF) were used to model concrete dynamics strength increment to investigate the influence of using different DIFs on the numerical predictions of RC wall responses to blast loadings. It is concluded that CEB-FIP Model overestimates the response in the strain rate range 1 20 s $\mathrm{s}^{-1}$ and it underestimates the response when strain rate exceeds $20 \mathrm{~s}^{-1}$ [48].

In the present study, the numerical analysis is carried out using the CEB-DIF value for concrete in compression as well as tension. No significant change is observed in the output of the simple numerical examples in this study and hence it is concluded that strain rate influence is not significant for this problem due to the associated low strain rate [49-50]. Previous studies show that the above material properties have been widely used to model RC structures, such as RC beams and RC panels [51-54]. The numerical results have given reliable predictions of RC structural responses to blast loading.

\subsubsection{Boundary conditions, application of blast loading and contact algorithm}

The RC beams are supported on two rigid plates shown in Fig. 1, which are made of solid elements to simulate the experimental conditions. Constraints are defined to the support plates. In the present numerical simulations, *LOAD_BLAST function in LS-DYNA is used to simulate blast loading. This function is mainly based on empirical relations derived from blasting tests and is developed based on a report by Randers-Pehrson and Bannister [55]. The advantage of this function is that it can avoid the detailed modelling of explosive charge and propagation of shock wave in air, thus save the calculation cost. This function has been proven reliable and widely applicable in simulating blast loading on structures [56-57]. It is noted that this function can't model the interaction between shock wave and structures, and it also ignores clearing effects of blast wave, however. Moreover, this function can not be used to study the influence of the shapes of explosive charges on the response of structures subjected to blast loading. Contact between the support plates and the RC beam is modeled through using the 
algorithm *CONTACT_AUTOMATIC_SINGLE_SURFACE in LS-DYNA. The algorithm automatically generates master and slave surfaces and a penalty method is used where nominal interface springs are used to interpenetration between surface and element. The interface stiffness is computed as a function of the volume, bulk modulus and face area of the elements on the contact surface.

\subsubsection{Finite element model and element erosion}

In this study, concrete is modeled by eight node solid hexahedron elements with a single integration point and beam elements (2-node Hughes-Liu beam element formulation with $2 \times 2$ Gauss quadrature integration) are used to model steel reinforcing bars. In order to capture the localized damage with high fidelity, the optimum element size is $5 \mathrm{~mm} \times 5 \mathrm{~mm} \times 5 \mathrm{~mm}$. A mesh convergence study is carried out to verify the selected element size can give convergence results for the $\mathrm{RC}$ beam. The mesh configuration in sectional directions comprises:

(1) In the width direction of the RC beam, 12 elements between two adjoining longitudinal reinforcements and 4 elements for concrete cover;

(2) In the depth direction of the RC beam, 12 elements for concrete between the bottom and top longitudinal reinforcements and 4 elements for concrete cover, in total, approximately, 90592 elements are used to model the beam B2-1.

The mesh discretization is carried out in such a way that the reinforcement steels nodes coincide with the concrete nodes. Beam elements connected to the concrete mesh nodes are used to model the reinforcement steels. The nodes that linked the concrete and reinforcement mesh are shared. The erosion algorithm is generally adopted to simulate physical fracture, shear failure, spalling and crushing of concrete material under blast loading. The erosion algorithm has been widely used in simulating the dynamic response of concrete under blast loading [58-60]. Gong et al. [61] used an erosion criterion according to the principle tensile strain of 0.001 to simulate the failure of concrete under blast loading. Considering convergence of numerical simulation and the above literature, an erosion criterion according to the principle tensile strain of 0.0015 in this study is adopted to model the failure of concrete 
and leads to reliable predictions of dynamic behavior of the RC beam.

\subsection{Numerical model calibration}

The maximum deflection at the mid-span of the RC beam specimen numbered for B2-1 is $9 \mathrm{~mm}$ according to the experimental study in Ref. [7], and the numerical simulation gives a value of $8.6 \mathrm{~mm}$ in this study as shown in Fig. 2. It is obvious that numerical results underestimate the maximum deflection at the mid-span of the RC beam subjected to blast loading. Moreover, numerical results are acceptable to describe the dynamic behaviors of RC beam subjected to blast loading within error permissibility ( $\sim 4.44 \%$ ). Figure 3 shows the failure characteristics obtained from the blasting test and numerical simulation. As shown in Fig. 3(a), no clear compressive crushing damage is observed on the top surface of the RC beam except for a small area at the edge of the beam in the experimental study. In the numerical simulation, the damage form is also reasonably reproduced as shown in Fig. 3(b). Fig. 3(c, d) shows the comparison of the failure characteristics between experimental and numerical results at the bottom surface of the RC beam. Compared with the experimental study, the numerical simulation could well capture the major cracks of the $\mathrm{RC}$ beams. As for the reasons why the numerical results underestimate the maximum deflection at the mid-span of the RC beam subjected to blast loading, it may be associated with both ignoring the effect of bond and slip between steel and concrete and adopting the CEB-DIF model. In conclusion, the above numerical model leads to reasonable predictions of the response of RC beams subjected to blast loading within error permissibility.

\section{Numerical simulations}

\subsection{Finite element model of pre-cracked RC beam}

It is noted that numerical simulation on the dynamic performance of RC beam under air blast loading mainly depends on dimensions of beam, boundary conditions, and material properties of concrete and reinforcement confinements. Due to having the same dimensions, boundary conditions and material models as the perfect RC beam, the calibrated model based on the testing data on the perfect RC beam above in this study is considered 
reliable for simulating the dynamic behavior of pre-cracked RC beams. Finite element model of the pre-cracked RC beam is shown in Fig. 4.

\subsection{Results and discussion}

\subsubsection{Influence of different weights of explosive charges}

In order to study the influence of different weights of explosive charges on the dynamic behavior of perfect RC beam (or pre-cracked RC beam), TNT charges of four different weights (300 g, $500 \mathrm{~g}, 700 \mathrm{~g}$, and $900 \mathrm{~g}$ ) detonated above the mid-span top of perfect RC beam (or pre-cracked RC beam) are taken into consideration. The explosive distance is $50 \mathrm{~cm}$, which is measured from the center of the TNT charge to the top surface of the RC beam. For the pre-cracked RC beam shown in Fig. 5, the depth D and width $\mathrm{C}$ of initial crack are $20 \mathrm{~mm}$ and $2.8 \mathrm{~mm}$, respectively. It is observed that the maximum deflection on the mid-span of the pre-cracked RC beam (or perfect RC beam) increases with increasing weight of TNT charges shown in Fig. 6(a, b). Compared with the perfect RC beam, it can be seen from Fig. 6 and Fig. 7 that the pre-cracked RC beam presents an increase in the maximum deflection under the same blast loading. Meanwhile, under the conditions of the same explosive distance, after reaching its maximum deflection at the relatively small amounts of TNT charges (e.g. $300 \mathrm{~g}$ ), the prefect RC beam (or pre-cracked RC beam) could vibrate freely with smaller amplitude. Moreover, the cracks on the pre-cracked RC beam could close down completely during the free vibration phase. With the increasing of TNT charges (e.g. 900 g), the prefect (or pre-cracked) RC beams could get larger deformation, which result in the failure of concrete at the mid-span and supports of the prefect (or pre-cracked) RC beam. At the same time, compared with the prefect RC beam, the existing cracks could cause the failure of the pre-cracked RC beam prematurely.

The pre-cracked RC beam also presents an increase in the effective stress of concrete in mid-span compressive zone in Fig. 8 (a) and axial stress of longitudinal reinforcement in mid-span tensile zone in Fig. 8 (b). When detonating $300 \mathrm{~g}$ TNT charge above the mid-span of the perfect RC beam, the effective stress of concrete is 36.9 MPa and axial stress of longitudinal reinforcement is $222.9 \mathrm{MPa}$. For the pre-cracked RC beam, the effective stress 
of concrete reaches 63.07 MPa with an increase of $70 \%$ and the longitudinal reinforcement reaches the yield strength $395 \mathrm{MPa}$. That is, the concrete in mid-span compressive zone of the perfect RC beam had maximum concrete stress, which is less than compressive strength of concrete (40 MPa). The yielding of longitudinal reinforcement could not be considered due to not reaching the yield strength. After reaching its maximum deflection, the prefect (or re-cracked) RC beam could vibrate freely with smaller amplitude. The concrete in mid-span compressive zone of the pre-cracked RC beam was crushed under the same blast loading, however. The damage distribution of the pre-cracked RC beam at different times under the conditions of the same TNT charge (900 g) is shown in Fig. 9. It is obvious that the presence of the initial cracks results in an evident concentration of strength failure at the pre-cracked section because of stress concentration. The existing crack can affect the dynamic behavior of pre-cracked RC beam under the same blast loading and result in the failure of the RC beam prematurely.

\subsubsection{Influence of different blasting positions}

Numerical simulations are conducted to study the influence of crack's presence under different blasting positions. The details of numerical simulation are presented in Table 4. The detonating positions of TNT charges are changed from the mid-span top to the quarter-span top of the RC beam.

The deflections on the mid-span of the pre-cracked RC beam (or perfect RC beam) under different detonating positions are shown in Fig. 10. Compared the TNT charge detonated above the quarter-span top of the beam with detonated above the mid-span top of the RC beam, the perfect RC beam (or pre-cracked RC beam) presents itself with an increase in the maximum deflection on the mid-span of the RC beam. When the TNT charge is detonated above the quarter-span top of the beam, the maximum deflection of the pre-cracked RC beam is still larger than that of the perfect RC beam. Under blast loading, maximum vertical velocity of the mid-span node of RC beam appears at the end of the shock wave, and then RC beam could continue moving downward due to inertia effect.

Fig. 11 shows vertical velocity history curve of the mid-span node of the pre-cracked RC beam (or perfect RC 
beam) under different detonating positions of TNT charges. Compared with TNT detonated above the quarter-span top of the beam, it can be seen that the perfect $\mathrm{RC}$ beam (or pre-cracked RC beam) presents itself with an increase in the maximum vertical velocity of the mid-span node on the conditions of TNT charge detonated above the mid-span top of the beam. Either TNT charge is detonated above the mid-span top or quarter-span top of the beam, the maximum vertical velocity of the mid-span node of the pre-cracked RC beam is always larger than that of the perfect RC beam. When the maximum vertical velocity of the mid-span node of the RC beam reduces to zero, it is found that the mid-span deflection of the beam reach maximum value.

Fig. 12 shows the comparison of damage distributions at different times between the perfect RC beam and the pre-cracked RC beam when $500 \mathrm{~g}$ TNT charge is detonated above the quarter-span top of the RC beam. It can be seen that for the perfect $\mathrm{RC}$ beam (or pre-cracked $\mathrm{RC}$ beam), the new formed cracks firstly appear near the quarter-span of the beam (the positions for blast loading begin to be loaded). With the increase of the bending deformation of the RC beam, the perfect RC beam finally breaks near the quarter-span of the beam and at other sections of the beam in Fig.12 $\left(a_{4}\right)$. The pre-cracked RC beam only breaks near the quarter-span of the beam (the positions for blast loading begin to be loaded) and at cracked section in Fig. 12( $\left.b_{4}\right)$, however.

\subsubsection{Influence of the different widths of initial cracks}

In order to study the influence of initial crack widths, the widths of the initial cracks are taken to be $0.28,0.21$, and $0.35 \mathrm{~cm}$, respectively and the depth of crack is fixed $20 \mathrm{~mm}$ on the pre-cracked RC beam. TNT charge is detonated above the mid-span top of the pre-cracked RC beam. Fig. 13(a) shows the mid-span deflection in time of the pre-cracked RC beam with different crack widths under blast loading.

Effective stress history curve of concrete in mid-span compressive zone and axial stress history curve of longitudinal reinforcement in mid-span tensile area of the pre-cracked RC beam with different initial widths of cracks are shown in Fig. 14 (a) and Fig. 15 (a), respectively. The damage distribution of the pre-cracked RC beam with different crack widths subjected to blast loading is shown in Fig. 16. 
In conclusion, the damage generated by blast loading effects is limited to a local area in all the cases considered in the present study. Based on the mid-span deflection of the RC beam, stress of concrete and longitudinal reinforcement and damage distribution of the pre-cracked RC beam subjected to blast loading, it is obvious that the width of the initial crack has minor influence on the dynamic behavior of the pre-cracked RC beams.

\subsubsection{Influence of the depths of initial cracks}

The influence of crack depths is considered in this section. The width of the initial crack is $0.28 \mathrm{~mm}$, but the depths of the initial crack are taken to be $(2,3$, and 4) cm, respectively. $500 \mathrm{~g}$ TNT is detonated above the mid-span top of the pre-cracked beam. Fig. 15 (b) exhibits the mid-span deflection in time of pre-cracked RC beam with different depths of crack under blast loading. Effective stress history curve of concrete in compressive zone and axial stress history curve of longitudinal reinforcement in tensile area of pre-cracked RC beam with different crack depths are shown in Fig. 14 (b) and Fig. 15 (b), respectively. The damage distribution of pre-cracked RC beam subjected to blast loading is shown in Fig. 17. According to the mid-span deflection, stress of concrete and longitudinal reinforcement and damage distribution of pre-cracked RC beam subjected to blast loading, it can be concluded that the crack depth also has minor influence on the dynamic behavior of the pre-cracked RC beam.

\subsubsection{Influence of the locations of initial cracks}

In this section, numerical simulations are conducted to study the influence of crack location. The numerical simulation details are given in Table 5. A pre-crack at a distance of $0 \mathrm{~L}$ (mid-section), L/4, L/2, 3L/4 or L (one end) away from the mid-section of the beam is considered. TNT is detonated above the mid-span top of the RC beam.

Fig. 18 shows the displacement history curves of the mid-span node of displacement history curves of the mid-span node of pre-cracked RC beam with different crack locations under blast loading. The results showed that the influence of the initial cracks is highly location-dependent and surface-dependent. As shown in Fig. 18 (a), a crack located at the mid-section or at one end of the pre-cracked RC beam leads the beam to have a much larger maximum deflection of mid-span than that located at other sections of the beams. Compared with the perfect RC 
beam (maximum deflection of mid-span: $0.63 \mathrm{~cm}$ ), a pre-crack located at $3 \mathrm{~L} / 4$ only has a minor effect on the maximum deflection at mid span of the RC beam, and that located at L/4 or L/2 has even negligible effect. Compared Fig. 18(a) with Fig. 18 (b), it is concluded that the initial cracks located on the compressive zone have greater influence on the maximum deflection of mid-span than that located on the tensile zone of the pre-cracked RC beam. Fig. 19 shows the comparison of maximum deflection vs different crack locations in the tensile zone of the pre-cracked beam. In can be seen that, when the initial cracks located in the tensile zone of the RC beams, the cracks located at the mid-section (or at one end of the beam) leads the concrete in mid-span compressive zone of $\mathrm{RC}$ beam to have larger maximum deflection than that located at other sections of the RC beam.

Fig. 20(a, b) shows the stress history curves of concrete and longitudinal reinforcement. It can be seen that the axial stress of longitudinal reinforcement in mid-span tensile zone of the RC beam with the initial crack located at the mid-section reaches the yield strength $395 \mathrm{MPa}$. It is larger than that of the RC beam with initial cracks located at other sections. For the pre-cracked RC beam with a crack located at one end, the peak value of axial stress of longitudinal reinforcement in mid-span tensile zone is $355 \mathrm{MPa}$, which is close to the yield strength. Compared with located on the tensile surface of the pre-cracked RC beam, when the initial crack located on the compressive surface, the effective stress of concrete in mid-span compressive zone is only $10.13 \mathrm{MPa}$. The axial stress of longitudinal reinforcement in mid-span tensile zone is $426 \mathrm{MPa}$, which reaches the yield strength, however. It can be seen that the initial crack located at the RC beam's mid-span or the ends has greater influence than that located at other sections of the RC beam. It should also be noted that in the present study, the explosives are placed at locations directly face the mid-span of the RC beam in all the cases considered. The damage of the pre-cracked RC beam generated by blast loading effects is limited to a local area. Therefore, the locations of cracks affected the responses of the pre-cracked RC beam.

\subsubsection{Influence of longitudinal reinforcement ratios}

Besides the dimensions and locations of cracks, the reinforcement of pre-cracked RC beam could also influence 
the dynamic behavior because reinforcement cage provides confinement to the concrete and bears loads. Four different diameters $(6 \mathrm{~mm}, 8 \mathrm{~mm}, 10 \mathrm{~mm}$, and $12 \mathrm{~mm})$ of longitudinal reinforcement are considered in this section. The corresponding longitudinal reinforcement ratios are $1.13 \%, 2.01 \%, 3.14 \%$, and $4.52 \%$, respectively. $500 \mathrm{~g}$ TNT charge is detonated above the mid-span top of the pre-cracked RC beam. More numerical simulation details are shown in Table 5. It can be seen from Table 5 that the maximum deflection on the mid-span of the pre-cracked RC beam decreases with the increase of longitudinal reinforcement diameter. That is to say, the anti-explosion quality of the RC beam is improved to some extent. Compared with the pre-cracked RC beam with $6 \mathrm{~mm}$ longitudinal reinforcement diameter, the mid-span maximum deflection in pre-cracked RC beam with the longitudinal reinforcement diameters of $8 \mathrm{~mm}, 10 \mathrm{~mm}$, and $12 \mathrm{~mm}$ decrease about 32\%, 48\%, and 57\%, respectively.

The stress history curve of concrete and longitudinal reinforcement and the damage distribution of pre-cracked RC beam can be observed in Fig. 21 and Fig. 22. It can be clearly observed that the peak values of effective stress of concrete in the compressive zone of mid-span are all in the range of $60 \mathrm{MPa}$, except for that on the pre-cracked $\mathrm{RC}$ beam with $1.13 \%$ longitudinal reinforcement ratio, which reached about $70 \mathrm{MPa}$. It is indicated that the confinement of rebar could mitigate the damage of concrete to some extent. Meanwhile, for the pre-cracked RC beams with the longitudinal reinforcement diameters of $6 \mathrm{~mm}, 8 \mathrm{~mm}$, and $10 \mathrm{~mm}$, the peak value of axial stresses of longitudinal reinforcement in mid-span tensile zone are $460 \mathrm{MPa}, 431 \mathrm{MPa}$ and $401 \mathrm{MPa}$, respectively. All of the peak values of axial stresses of longitudinal reinforcement reach the yield strength $395 \mathrm{MPa}$. Compared with that of the pre-cracked RC beam with $6 \mathrm{~mm}$ longitudinal reinforcement diameter, for pre-cracked RC beam with $12 \mathrm{~mm}$ longitudinal reinforcement diameter, the peak value of axial stress of longitudinal reinforcement in mid-span tensile area reduces to $309 \mathrm{MPa}$ with a decrease of $33 \%$, however. In conclusion, the increase of reinforcement ratio could expand the reinforcement area, improve the tensile strength, and reduce the stresses of concrete and longitudinal reinforcement. Therefore, the flexural capacity of the component is increased and the corresponding anti-explosion ability is also enhanced to some extent. The pre-cracked RC beams with higher longitudinal reinforcement ratio 
(e.g. 3.14\%), could result in the brittle failures. While the pre-cracked RC beams with lower longitudinal reinforcement ratio (e.g. $1.13 \%$ ) could lead to ductile behavior.

\section{Conclusions}

In this paper, finite element model is verified first through simulation of a previous experimental test reported in the literature. Then, parametric studies are carried out to study the influence of weights and positions of explosive charges, and locations, widths and depths of cracks, and longitudinal reinforcement ratios on the dynamic behavior of the simple supported pre-cracked RC beam. The simulated results show that, compared with the perfect beams, the pre-cracked RC beams present themselves with an increase in the maximum deflection of mid-span, the maximum vertical velocity of mid-span node, effective stresses of concrete in compressive zone of the beam and axial stresses of longitudinal reinforcement in tensile area of the RC beam. Due to stress concentration of the pre-cracked sections under air blast loading, the presence of initial cracks at the mid-span (or the end of RC beam) could cause the failure of RC beam prematurely at the cracked sections and where the blast loading begin to be loaded. The initial cracks on the surface of compression zone have larger influence than that on the surface of tensile zone of the pre-cracked RC beam. The damage generated by blast loading effects is limited to a local area, and the dynamic behavior of the pre-cracked $\mathrm{RC}$ beam is not sensitive to the width and depth of initial cracks to some extent. Finally, it is emphasized that, the conclusions obtained are solely based on illustrative analysis of the simple numerical examples in this study. In view of the facts that some cracks are formed on the casting process of $\mathrm{RC}$ beam, and other are formed due to the propagation of these original cracks in use, the dynamic behavior of the simple supported pre-cracked RC beam with initial cracks subjected to air blast loading may be different due to the personality characteristics and complicated affecting factors of the formed cracks. Therefore, generalization of the conclusions may not be immediately valid, especially when the width and depth of initial cracks on the simple supported pre-cracked RC beam are larger than $0.35 \mathrm{~cm}$ and $4 \mathrm{~cm}$, respectively. Hence further study is required.

\section{Acknowledgements}


This research was financially supported by the National Science Foundation of China (grand no. 11302094, 11302093, and 51479168), the National Science Foundation of Liaoning province in China (grand no. 2015020214); the Program for Liaoning Excellent Talents in University (grand no.LJQ2014063).

\section{References:}

[1] Guzas E L, Earls C J. Simulating blast effects on steel beam-column members: applications. Comput Struct 2011; 89:2149-61.

[2] Corley W G. Lessons Learned on improving resistance of buildings to terrorist attacks. J Perform Constr Fac 2004; 18: 68-78.

[3] Qu Y D, Wu M, Wang J L, Kong X Q. Study on the structure failure of the masonry buildings under the flammable gas explosion. Journal of Bohai University (Nat Sci Edit) 2013; 34(9): 323-7.

[4] Li J, Hao H. Numerical study of concrete spall damage to blast loads. Int J Impact Eng 2014; 68:41-55.

[5] Qu Y D, Li X J, Yan H H, Liu H X. Overpressure comparison of blasting in air and special-made hemispherical structure. Chin J High Pressure Phys 2012; 26: 95-101.

[6] Yong L, Kai X. Modelling of dynamic behaviour of concrete materials under blast loading. Int J Solids Struct 2004; 41(1):131-43.

[7] Zhang D, Yao S J, Lu F Y, Chen X G, Lin G H,Wang W, Lin Y L. Experimental study on scaling of RC beams under close-in blast loading. Eng Fail Anal 2013; 33:497-504.

[8] Ohtsu M, Uddin Fakm, Tong W, Murakami K. Dynamics of spall failure in fiber reinforced concrete due to blasting. Constr Build Mater 2007; 21:511-8.

[9] Wang W, Zhang D, Lu F, Wang S-C, Tang F. Experimental study on scaling the explosion resistance of a one-way square reinforced concrete slab under a close-in blast loading. Int J Impact Eng 2012; 49: 158-64.

[10] Magnusson J, Hallgren M, Ansell A. Air-blast-loaded, high-strength concrete beams. Part I: Experimental investigation. Mag Concr Res 2010; 62:127-136. 
[11] Magnusson J, Hallgren M. Reinforced high strength concrete beams subjected to air blast loading. In: Jones N, Brebbia C A, editors. Structures under shock and impact VIII. Southampton: WIT Press; 2004. p. 53-62.

[12] Chen W X, Yan S H. Experimental study of RC beams strengthened with CFRP under blast loading. China Civil Engineering Journal 2010; (5):1-9.

[13] Ohtsu M, Uddin F A K M, Tong W, Murakami K. Dynamics of spall failure in fiber reinforced concrete due to blasting. Constr Build Mater 2007; 21(3):511-18.

[14] Wang W, Zhang D, Lu F, Wang S C, Tang F. Experimental study on scaling the explosion resistance of a one-way square reinforced concrete slab under a close-in blast loading. Int J Impact Eng 2012; 49(2):158-64.

[15] Codina R, Ambrosini D , Borbón F. Experimental and numerical study of a RC member under a close-in blast loading. Struct Eng 2016;127:145-58.

[16] Qu Y D, Li X, Kong X Q, Sun C H. Research progress of blast-resistant performance of reinforced concrete beams under blast loads and reinforcement technology. Science Technology Review 2016; 34(2): 99-103.

[17] Zhou X Q, Kuznetsov V A, Hao H, Waschl J. Numerical prediction of concrete slab response to blast loading. Int J Impact Eng 2008; 35:1186-200.

[18] Zhou X Q, Hao H. Mesoscale modeling and analysis of damage and fragmentation of concrete slab under contact detonation. Int J Impact Eng 2009; 36:1315-26.

[19] Li J, Wu C, Hao H. Investigation of ultra-high performance concrete slab and normal strength concrete slab under contact explosion. Eng Struct 2015; 102:395-408.

[20] Mazurkiewicz L, Malachowski J, Baranowski P. Blast loading influence on load carrying capacity of I-column Eng Struct 2015; 104:107-15.

[21] Xu J C, Wu C Q, Xiang H B, Su Y, Li Z X, Fang Q, Hao H, Liu Z X, Zhang Y D, Li J. Behaviour of ultra high performance fibre reinforced concrete columns subjected to blast loading. Eng Struct 2016; 118: 97-107.

[22] Mao L, Barnett S, Begg D, Schleyer G, Wight G. Numerical simulation of ultra high performance fibre reinforced concrete panel subjected to blast loading. Journal of Research on Christian Education 2014, 
64(64):91-100.

[23] Qu Y D, Li X, Kong X Q, Zhao Q. Analysis of pressure field and response for reinforced concrete beam under air blast loads. Concrete, 2016; (7):74-8.

[24] Xu K, Lu Y. Numerical simulation study of spallation in reinforced concrete plates subjected to blast loading. Comput Struct, 2006; 84:431-8.

[25] Dragos J, Wu C. Interaction between direct shear and flexural responses for blast loaded one-way reinforced concrete slabs using a finite element model. Eng Struct 2014; 72:193-202.

[26] Hudson J L, Darwin D. Evaluation and repair of blast damaged reinforced concrete buildings. SL report 05-1. Kansas (USA): University of Kansas Center for Research, Inc., Lawrence; 2005.

[27] Chondros T G, Dimarogonas A D. Vibration of a cracked cantilever beam. J Vib Acoust, 1998;120:742-6.

[28] Paik J K, Satish Kumar Y V, Lee J M. Ultimate strength of cracked plate elements under axial compression or tension. Thin-Walled Struct 2005; 43:237-72.

[29] Alinnia M M, Hosseinzadeh S A A, Habashi H R, Numerical modelling for buckling analysis of cracked shear panels, Thin-Walled Struct 2007; 45: 1058-67.

[30]Wu Z J, Davies J M. Mechanical analysis of a cracked beam reinforced with an external FRP plate. Compos Struct 2003, 62(2):139-43.

[31] Hallquist J O. LS-DYNA keyword user's manual. Volume I and II, Version 971 R6.0.0. California: Livermore Software Technology Corporation, 2012, pp. 246-249.

[32] Holmquist T J, Johnson G R, Cook W H. A computational constitutive model for concrete subjected to large strains, high strain rates, and high pressures, in: The 14th International Symposium on Ballistics, Quebec City, Canada, 1993, pp. 591-600.

[33] Bai J Z. Theoretical basis of LS-DYNA3D and analysis of cases. Beijing: Science Press, 2005.

[34] Johnson G R, Computed radial stresses in a concrete target penetrated by a steel projectile, in: Proceedings of 
the 5th International Conference on Structures under shock and impact, Portsmouth, UK, 1998, pp. 793-806.

[35] Tai Y S, Chu T L, Hu H T, Wu J Y. Dynamic response of a reinforced concrete slab subjected to air blast load, Theor Appl Fract Mech 2011; 56:140-7.

[36] Pan J L, Zhou J J, Luo M. Numerical simulations on dynamic responses of FRP strengthened reinforced concrete two-way slabs under blasting loading. Journal of PLA University of Science and Technology (Natural Science Edition) 2011;12(6):643-8.

[37] Xiang Q, Liu T, Wang R H. The failure mode of RC beams under blast loading. Journal of Yangtze University(Nat Sci Edit), 2011;8(7):89-91.

[38] Yuan L, Gong S F, Jin W L. Spallation Mechanism of RC slabs under contact detonation. Transactions of Tianjin University, 2008, 14(6):464-9.

[39] Malvar L, Crawford J. Dynamic increase factors for steel reinforcing bars. In: 28th DDESB seminar; 1998. Orlando, USA.

[40] Malvar L J, Crawford J E. Dynamic increase factors for concrete. DTIC Document, 1998.

[41] Béton CE-Id. CEB-FIP model code 1990: design code. Thomas Telford, 1993.

[42] Ekström J, Rempling R, Plos M. Spalling in concrete subjected to shock wave blast. Eng Struct 2016;122:72-82.

[43] Yan D, Lin G. Dynamic properties of concrete in direct tension. Cement Concrete Res 2006;36(7):1371-8.

[44] Liu M. A new dynamic increase factor for nonlinear static alternate path analysis of building frames against progressive collapse. Eng Struct 2013; 48:666-73.

[45] Li X, Chen J F, Lu Y, Yang Z. Modelling static and dynamic FRP-concrete bond behaviour using a local concrete damage model. Adv Struct Eng 2015;18(1):45-58.

[46] Malvar L J, Crawford J E, Morrill KB. K\&C Concrete material model release 3-automated generation of material model input, Technical Report TR-99-24.3, Karagozian and Case Structural Engineers, Glendale, CA. 
2000.

[47] Malvar LJ, Crawford JE, Wesevich J W, Simons D. A plasticity concrete material model for DYNA3D. Int J Impact Eng 1997;19(9-10): 847-73.

[48] Hao Y, Hao H. Influence of the concrete DIF model on the numerical predictions of RC wall responses to blast loadings. Eng Struct 2014; 73:24-38.

[49] Trivedi N, Singh R K. Prediction of impact induced failure modes in reinforced concrete slabs through nonlinear transient dynamic finite element simulation. Ann Nucl Energ 2013; 56(6):550-6.

[50] Lin X, Zhang Y X, Hazell P J. Modelling the response of reinforced concrete panels under blast loading. Mater Design 2014; 56(4):620-8.

[51] Li J, Hao H. Numerical study of structural progressive collapse using sub-structure technique. Eng Struct 2013; $52: 101-13$.

[52] Li J, Hao H. Influence of brittle shear damage on accuracy of the two-step method in prediction of structural response to blast loads. Int J Impact Eng 2013; 54:217-31.

[53] Zhao C F, Chen J Y. Damage mechanism and mode of square reinforced concrete slab subjected to blast loading. Theor Appl Fract Mech 2013; 63-64:54-62.

[54] Bi K, Hao H. Numerical simulation of pounding damage to bridge structures under spatially varying ground motions. Eng Struct 2013; 46:62-76.

[55] Randers-Pehrson G, Bannister K A. Air blast loading model for DYNA2D and DYNA3D. DTIC Document.

[56] Chen W, Hao H. Numerical study of a new multi-arch double-layered blast-resistance door panel. Int J Impact Eng 2012; 43:16-8.

[57] Gilson L, Van Roey J, C. Guéders, Gallant J, Rabet L. A simple coupling of ALE domain with empirical blast load function in LS-DYNA. EPJ Web of Conferences 2012; 26:04018.

[58] Coughlin A M, Musselman E S, Schokker A J, Linzell D. G. Behavior of portable fiber reinforced concrete 
vehicle barriers subject to blasts from contact charges. Int J Impact Eng 2010; 37:521-9.

[59] Tang E K, Hao H. Numerical simulation of a cable-stayed bridge response to blast loads, part I: model development and response calculations. Eng Struct 2010; 32:3180-92.

[60] Wu K-C, Li B, Tsai K-C. The effects of explosive mass ratio on residual compressive capacity of contact blast damaged composite columns. J Constr Steel Res 2011; 67: 602-12.

[61] Gong S F, Deng H, Zhu S B, Jin W L. Numerical simulation for dynamic failure of a reinforced concrete slab under close-in-explosion. J Vib Shock 2012; 31:20-4. 


\section{Figure Captions}

Fig.1 Schematic diagram of TNT charge and RC beam in the test

Fig. 2 Displacement history curves of the mid-span node of perfect RC beam under blast loading

Fig. 3 Comparison of failure characteristics of perfect RC beam: (a) top surface of the beam (test) [7];

(b) top surface of the beam (simulation); (c) bottom surface of the beam (test) [7]; (d) bottom surface of the beam (simulation)

Fig. 4 Finite element model: (a) pre-cracked RC beam; (b) details of mesh at the crack tip of pre-cracked RC beam

Fig. 5 Schematic diagram of the cracks on the pre-cracked RC beam (widths (D), depths (C) and locations of initial cracks (a))

Fig. 6 Displacement history curves of the mid-span node when detonating different TNT charges: (a) perfect RC beam; (b) pre-cracked RC beam

Fig. 7 Maximum deflection of the perfect (or pre-cracked) RC beam vs. explosive charges

Fig. 8 Stress history curves when detonating 300 g TNT charge above the mid-span of the perfect (or pre-cracked) RC beam: (a) effective stress history curve of concrete in mid-span compressive zone; (b) axial stress history curve of longitudinal reinforcement in mid-span tensile zone 
Fig. 9 Damage distributions of the pre-cracked beam for different times when detonating $900 \mathrm{~g}$ TNT charge

Fig. 10 Displacement history curve of the mid-span node of the different RC beam under different detonating positions of TNT charge: (a) perfect RC beam; (b) pre-cracked RC beam Fig. 11 Comparison of vertical velocity history curves of the mid-span node of RC beam under different detonating positions of TNT charge: (a) perfect RC beam; (b) pre-cracked RC beam Fig. 12 Comparison of damage distribution when $500 \mathrm{~g}$ TNT is detonated above the quarter-span top of the RC beam: $\left(a_{1}\right) \sim\left(a_{4}\right)$ : damage distribution of perfect RC beam; $\left(b_{1}\right) \sim\left(b_{4}\right)$ : damage distribution of pre-cracked RC beam

Fig. 13 Displacement history curve of the mid-span node of pre-cracked RC beam: (a) with different crack widths; (b) with different crack depths

Fig. 14 Effective stress history curve of concrete of pre-cracked RC beam: (a) with different crack widths; (b) with different crack depths

Fig. 15 Axial stress history curves of longitudinal reinforcement of pre-cracked RC beam with different: (a) crack widths; (b) crack depths

Fig. 16 Damage distribution of the pre-cracked RC beam with different crack widths: (a) $2.1 \mathrm{~mm}$; (b) $2.8 \mathrm{~mm}$; (c) $3.5 \mathrm{~mm}$

Fig. 17 Damage distribution of the pre-cracked RC beam with different crack depths: (a) $2 \mathrm{~cm}$; (b) 3 cm; (c) $4 \mathrm{~cm}$ 
Fig. 18 Displacement history curves of the mid-span node of pre-cracked RC beam under blast loading: (a) the initial crack located on different positions of the tensile surface; (b) the initial crack located on the tensile and compressive surface.

( $f$ or b: on the top or bottom surface of RC beam; L: half of the beam span )

Fig. 19 Comparison of maximum deflection vs different crack locations in the tensile zone of the pre-cracked beam ( $\mathrm{L}$ : half of the beam span)

Fig. 20 Stress history curves: (a) Effective stress history curve of concrete in mid-span compressive zone; (b) Axial stress history curve of longitudinal reinforcement in mid-span tensile zone ( $\mathrm{f}$ or b: on the top or bottom surface of RC beam; L: half of the beam span )

Fig. 21 Stress history curve of concrete and longitudinal reinforcement of the pre-cracked RC beam under blast loading: (a) effective stress of concrete in mid-span compressive zone; (b) axial stress of longitudinal reinforcement in mid-span tensile area

Fig. 22 Damage distribution of pre-cracked RC beam with different longitudinal reinforcement ratios under blast loading: (a) 1.13\%; (b) 2.01\%; (c) 3.14\%; (d) $4.52 \%$ 
Figures

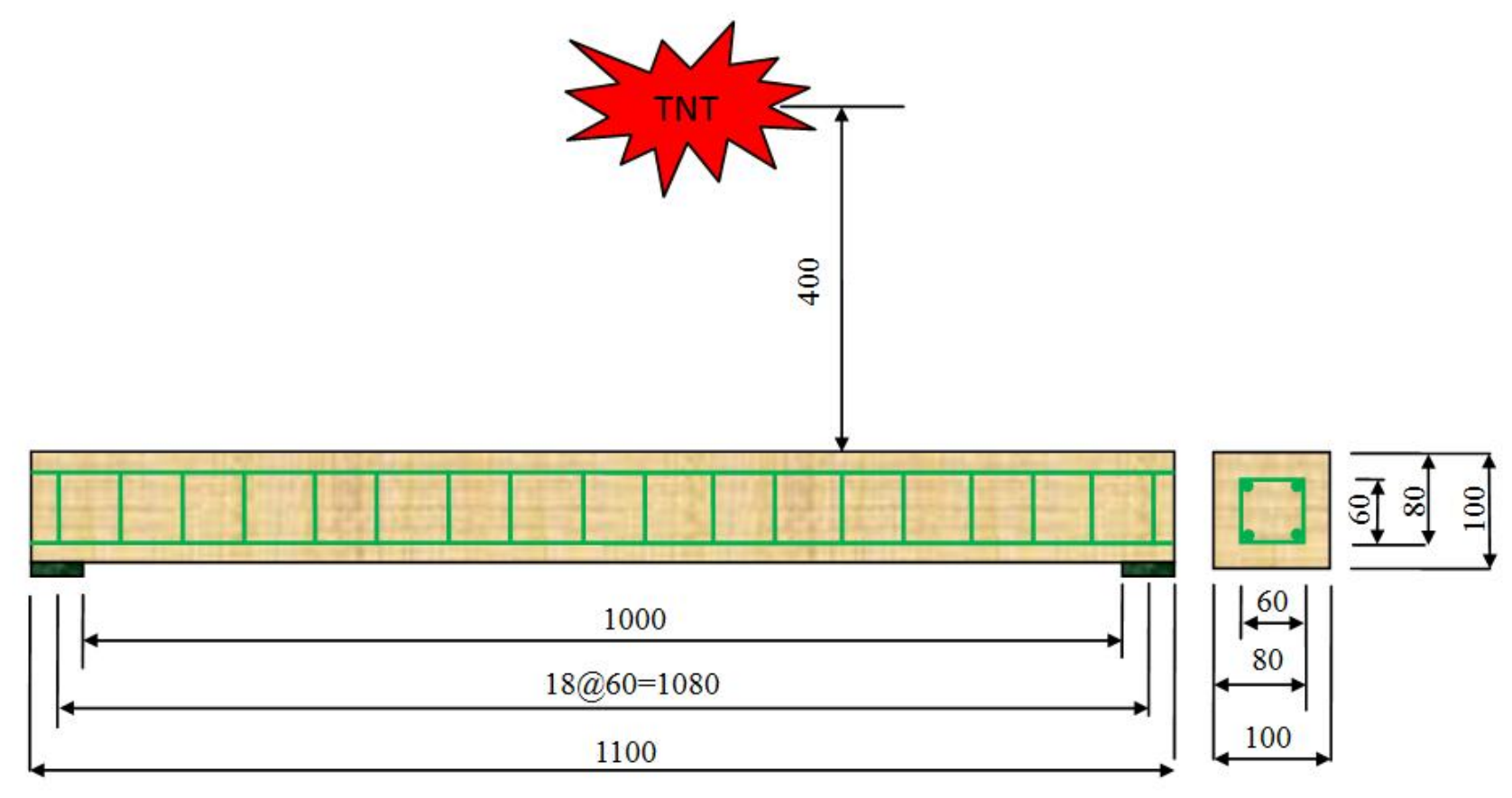

Fig.1 


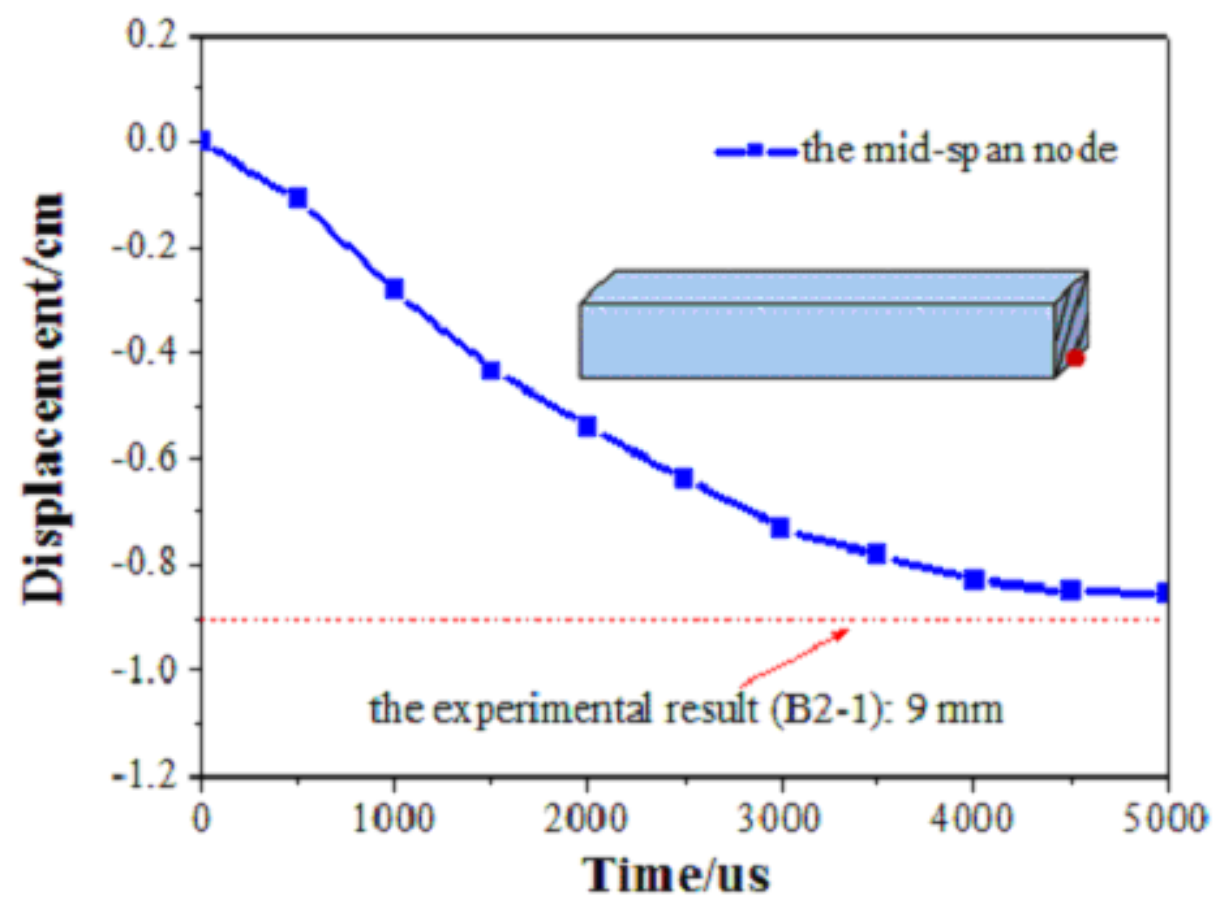

Fig. 2

(a)

(b)
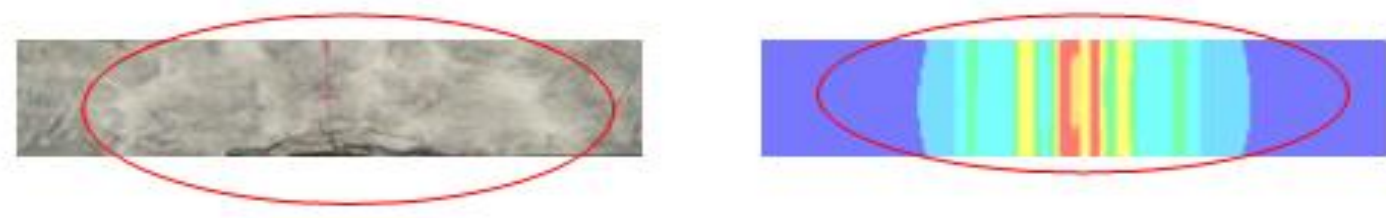

rringe Leveta

6.5910-04

6.9320-04

6.27ae-04

$4-6740-04$

3.956- 04

3. $2965-04$

2.097 e.04

1.0770-04

1.316e-04

6.6ste-0s

0,000000

(c)

(d)
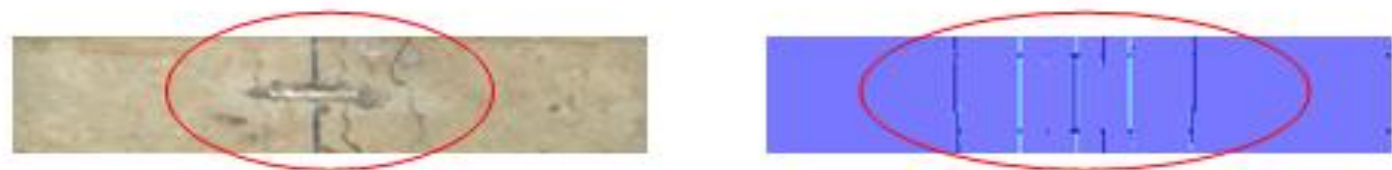

Cringe Levets

6.5915-04

6.9320-04

6.273e-04

4.6140 .04

3.965-0.04

3.296e-04

2.637 e.04

1.977e-04

1.318e-04

cosve-os

c,000e+00

Fig. 3 
(a)

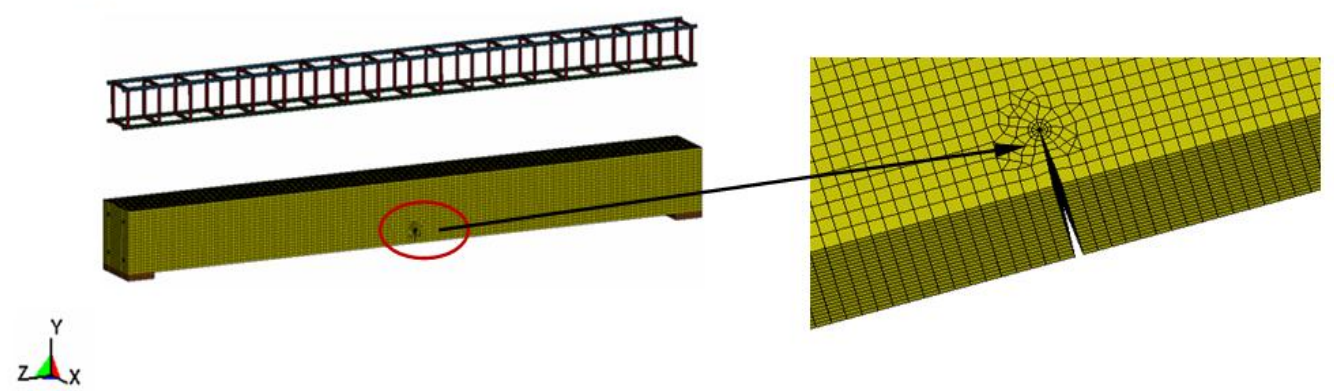

Fig. 4

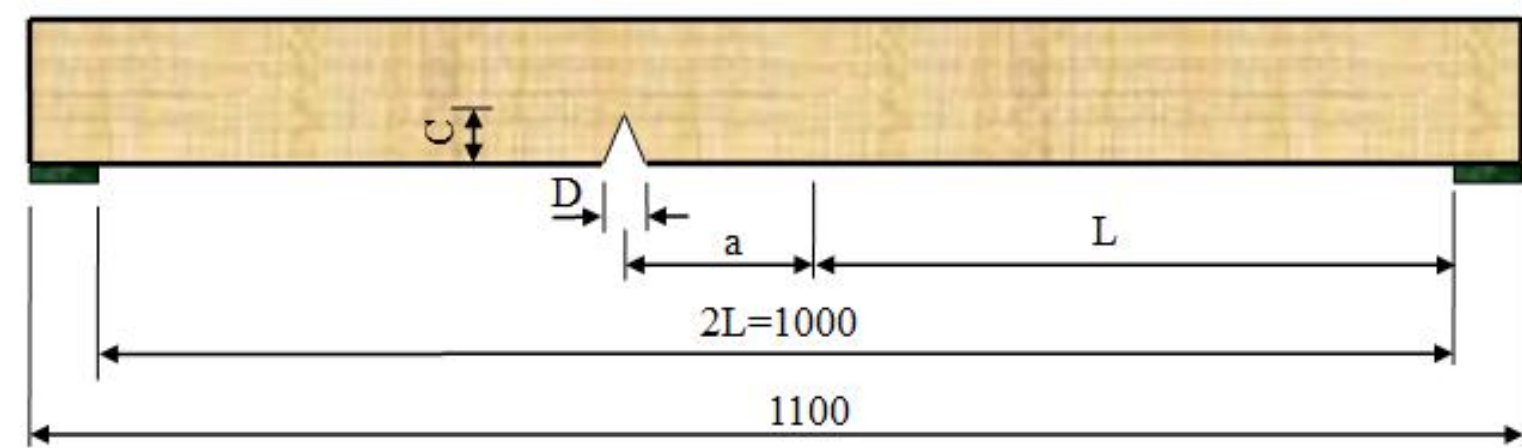

Fig. 5 

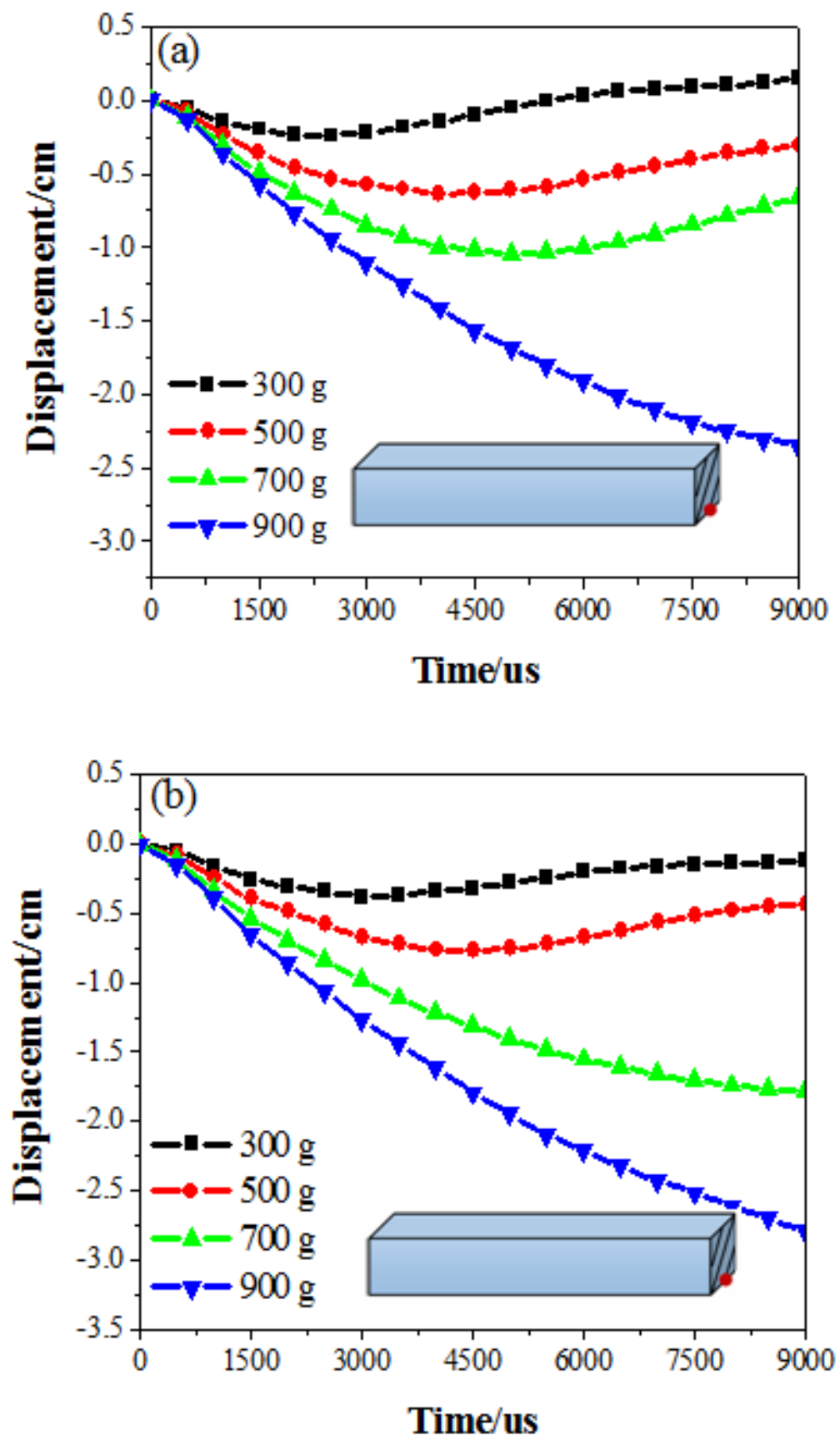

Fig. 6 


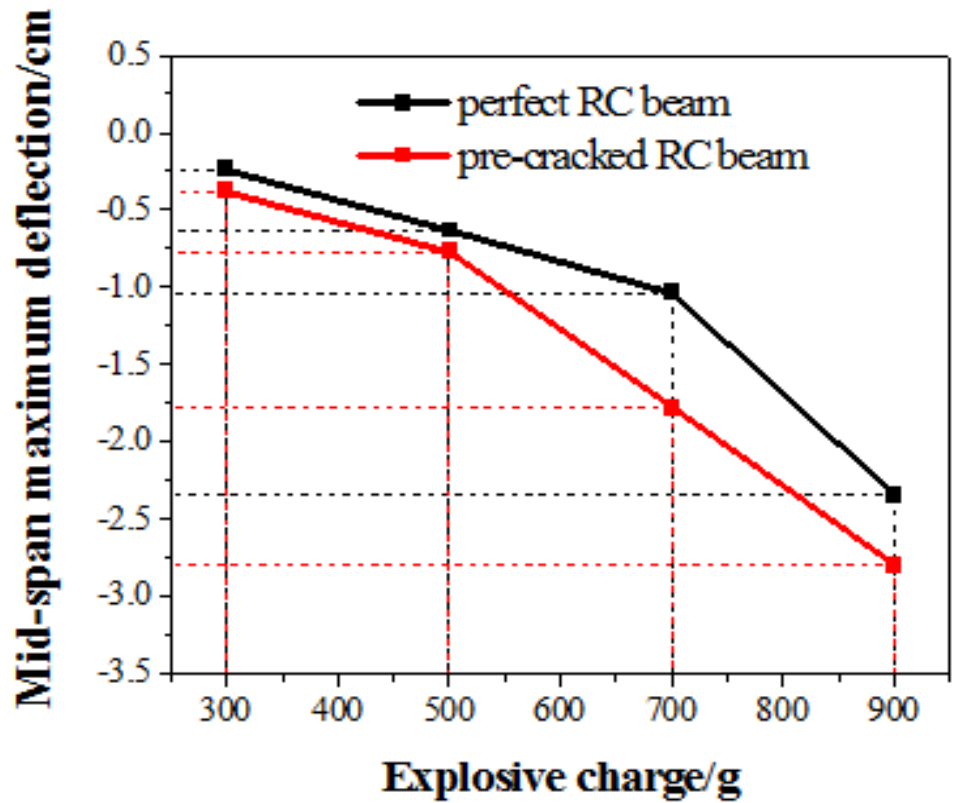

Fig. 7 

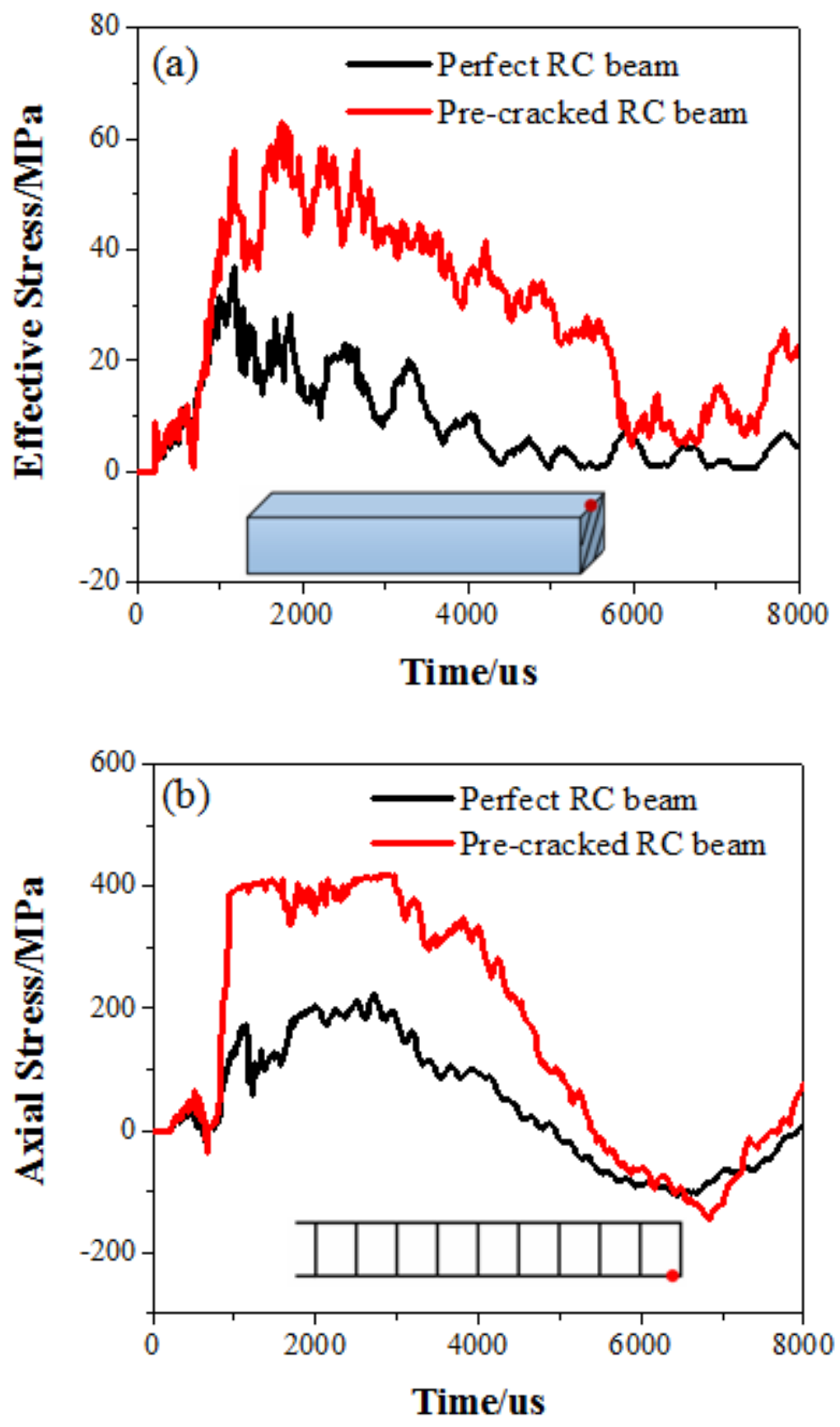

Fig .8 


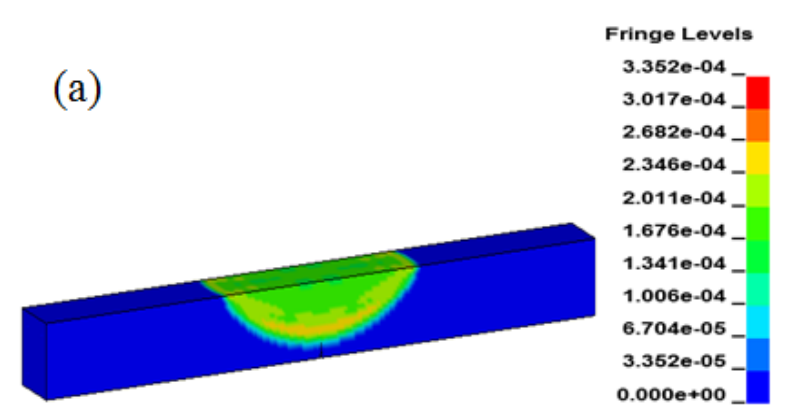

$\mathrm{t}=180 \mathrm{us}$

(c)

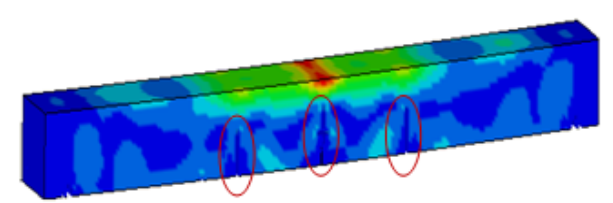

$\mathrm{t}=840 \mathrm{us}$

Fringe Levels 6.033e-04

5.430e-04 4.826e-04 4.223e-04

3.620e-04

3.016e-04

2.413e-04_

1.810e-04

1.207e-04 6.033e-05 $0.000 e+00$

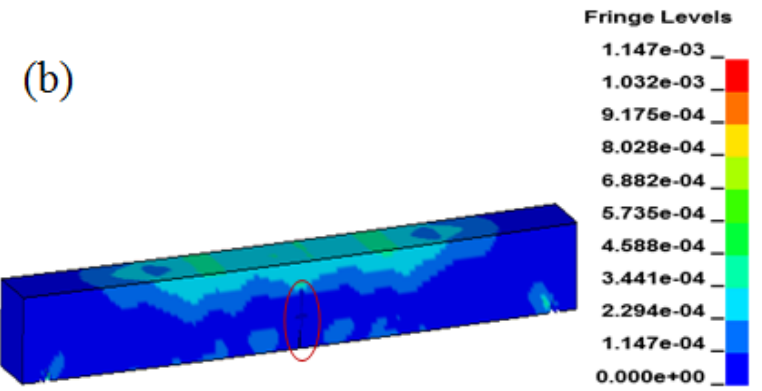

$\mathrm{t}=600 \mathrm{us}$

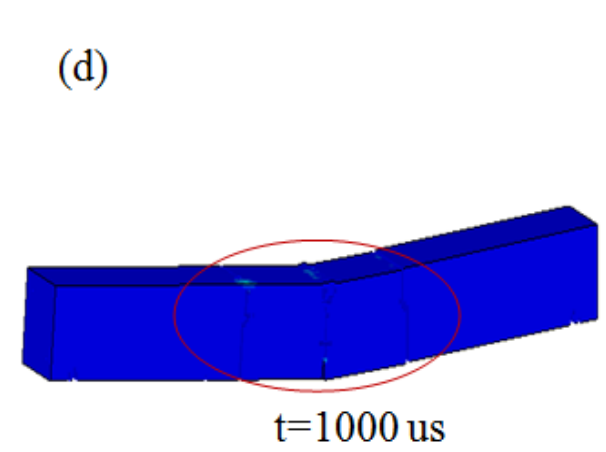

Fringe Levels 9.090e-04 8.181e-04_ $7.272 \mathrm{e}-04$ 6.363e-04 5.454e-04 4.545e-04 3.636e-04 2.727e-04 $1.818 \mathrm{e}-04$ 9.090e-05 $0.000 e+00 \_$

$\mathrm{t}=1000$ us

Fig. 9 

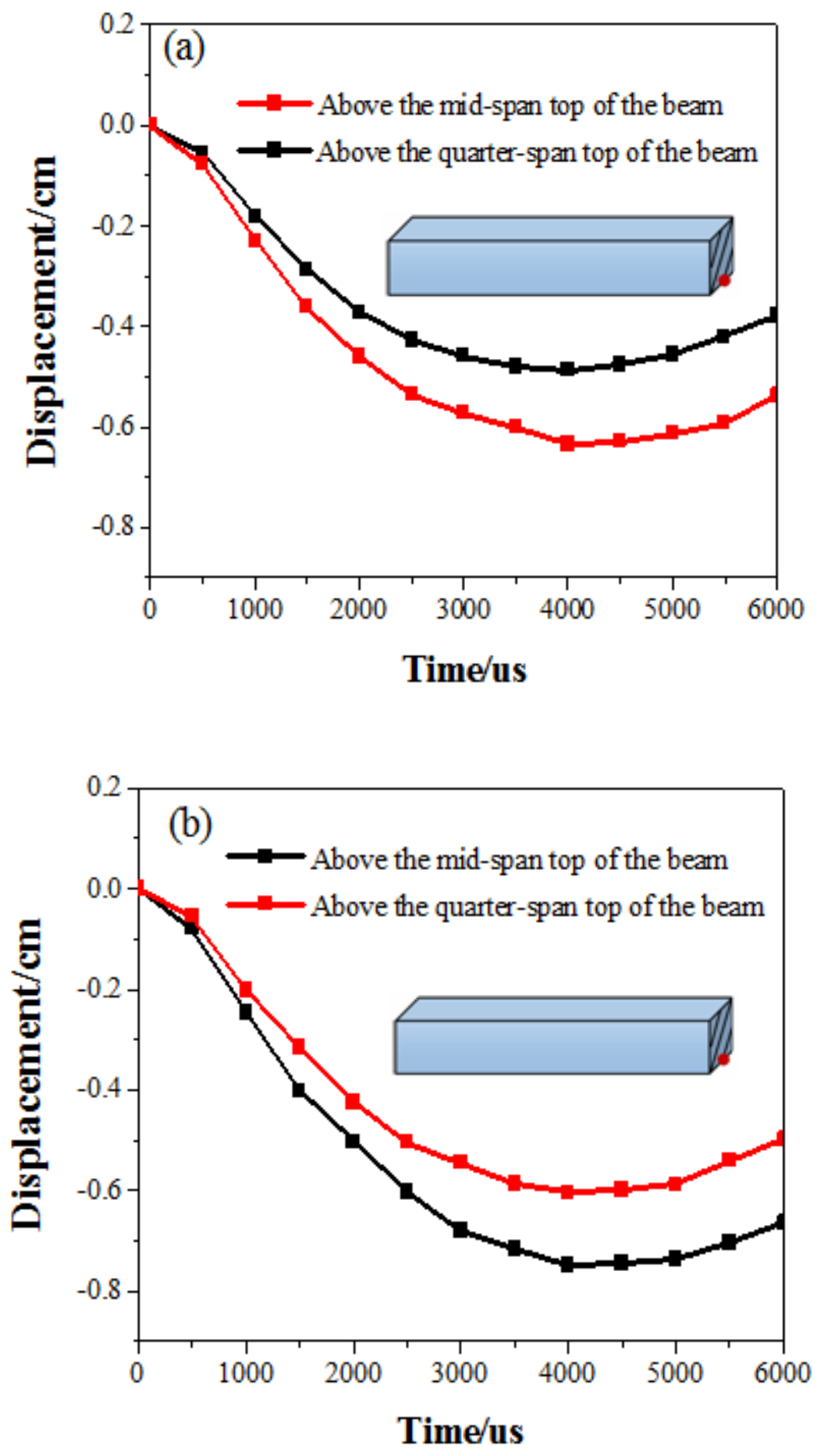

Fig. 10 

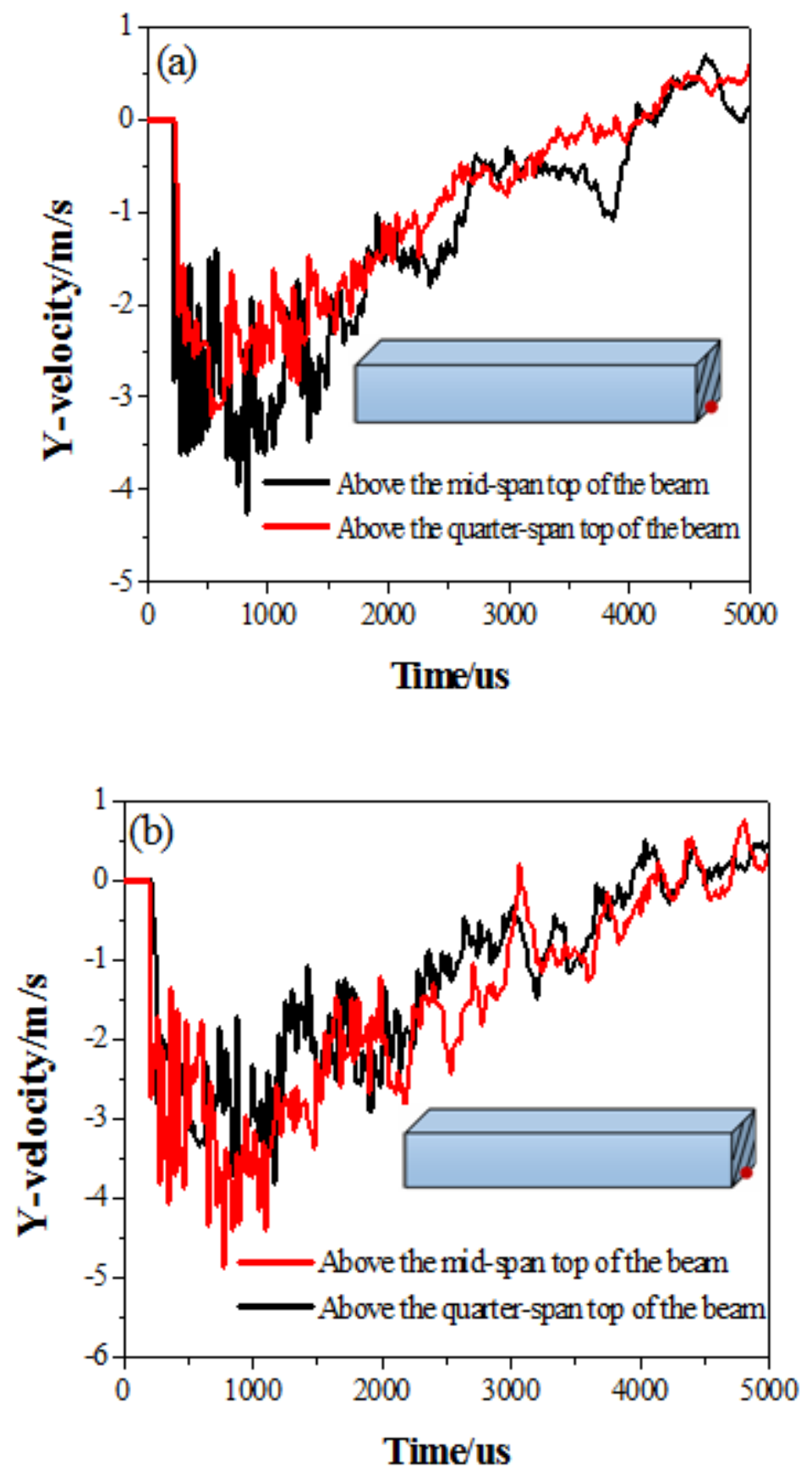

Fig. 11 


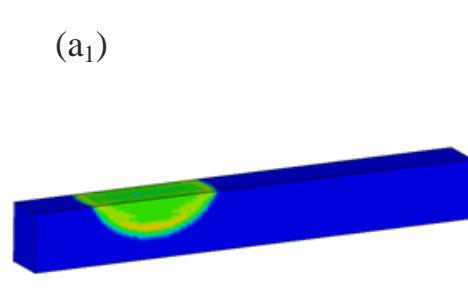

Fringe Leve

$2.2510-04$

2.0260 .04

$1.8010-04$

1.350004

1.1250 .04

1.0030

$9.0030-05$

$6.762 e-05$ -

22510.05

0.000

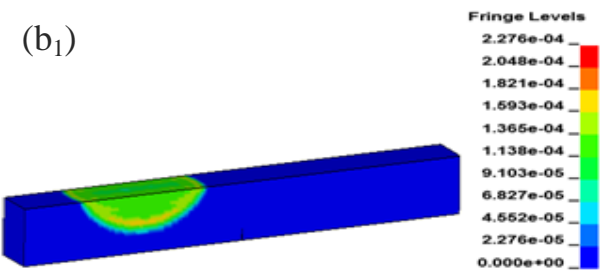

$t=200$ us

$\left(a_{2}\right)$

Fringe Levelo

7.253e-04

$6.0270 .04-$

$6.0770 .04-$

$\left(b_{2}\right)$

Fringe Levels

7.9550 .04

7.965e-04 -

4.3520 .04

4.3620 .04

$2.0010-04$

2.1760 .04

2.1760 .04
1.4510 .04

1.451e-04

7.263e-05

$t=540$ us

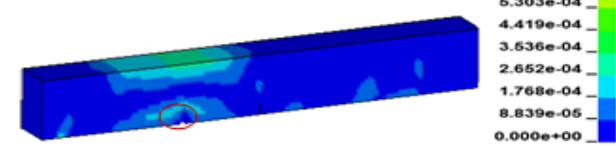

inge Lev

5.242e-0.4

$4.7186 .04-$

$3.6690-04$

$3.1450-04$

3.1450 .04
2.6210 .04
2.0970 .04

1.6730 .04

$1.673 e .04-$
1.0480 .04
6.2420 .06

1.0480.04 -

$0.0000+00$ _

$\mathrm{t}=1080$ us

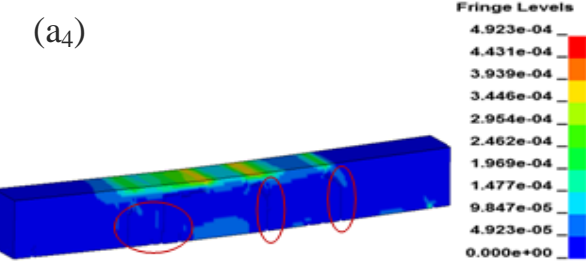

$\quad\left(b_{4}\right)$

$\left(b_{3}\right)$

Fringe Levels

7.631e.04-

$6.1050-04$

5.3420.04

4.5790 .04

$3.8160-04$

$3.0520 .04-$
$2.2890-04$

1.5260 .04

7.6310 .05 -

$.0000+00$

4.431e-04 -

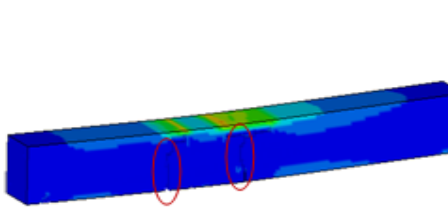

Fringe Levete

6.8490 .04

6.264e-04 4.0940 .04

$3.5090-04$

$2.0260-04$

$2.340 e-04$
$1.765 e-04$

$1700-04$

5.8490 .05

$\mathrm{t}=4000 \mathrm{us}$

$0.0000+00$

Fig. 12 

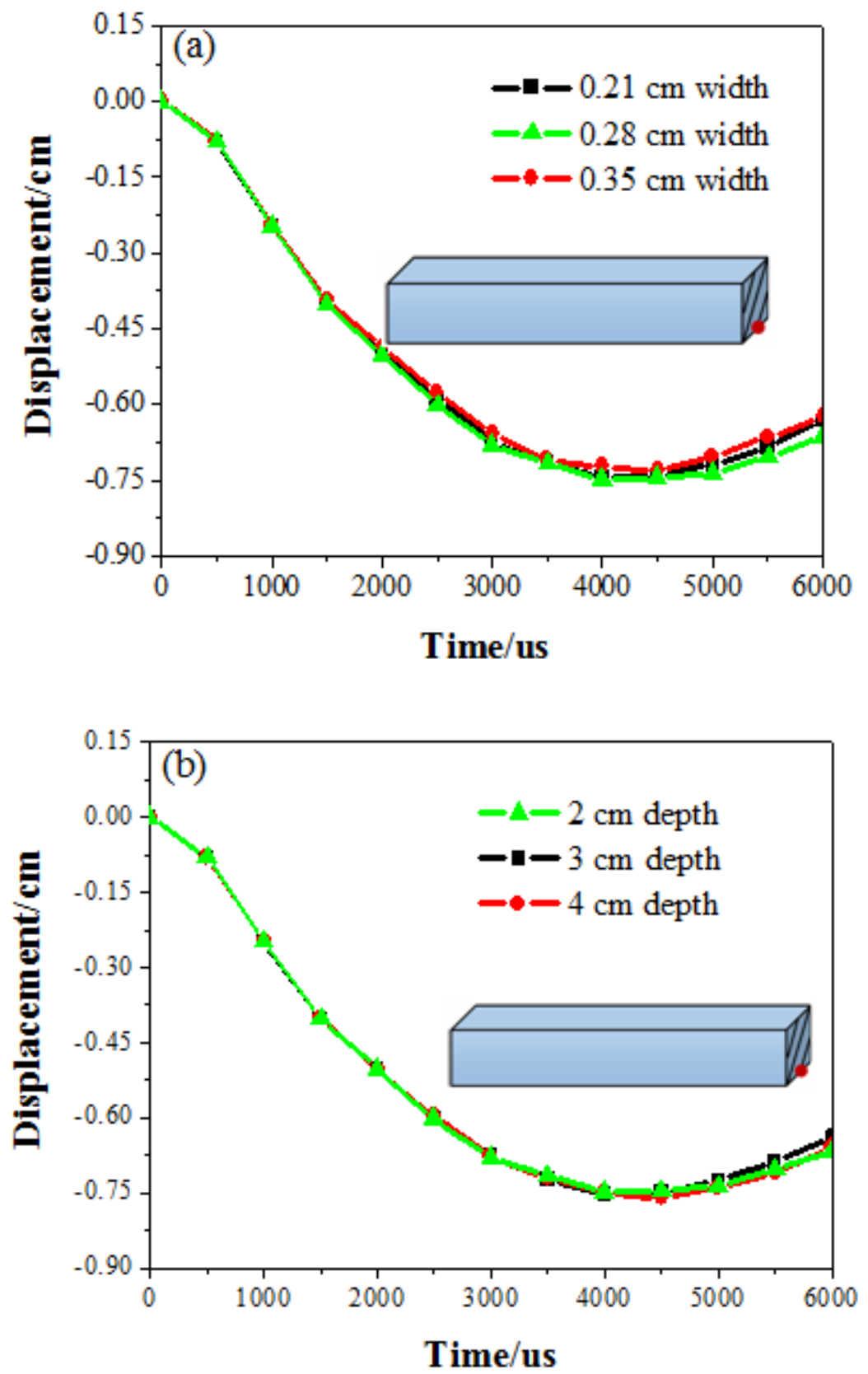

Fig .13 

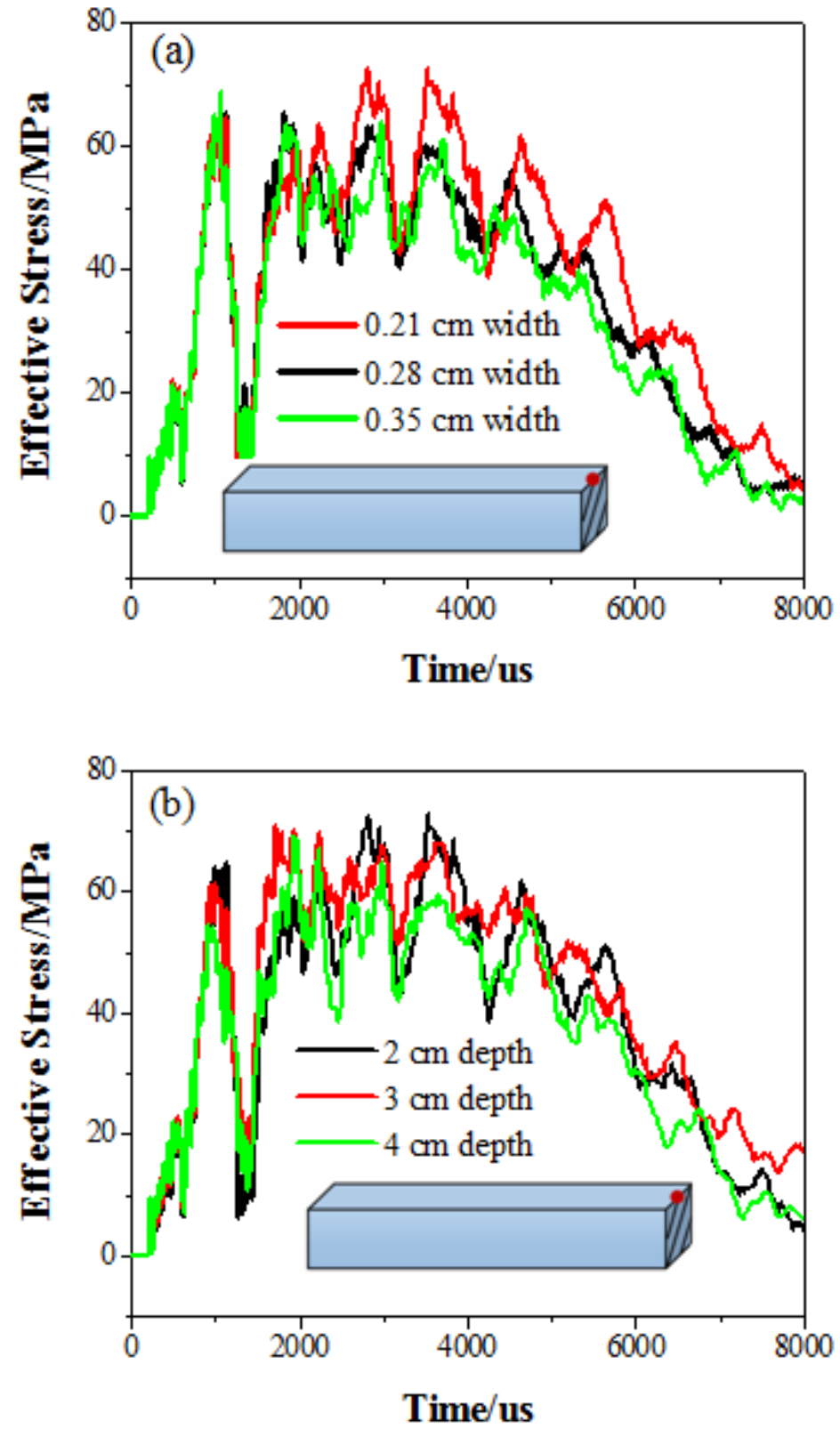

Fig. 14 

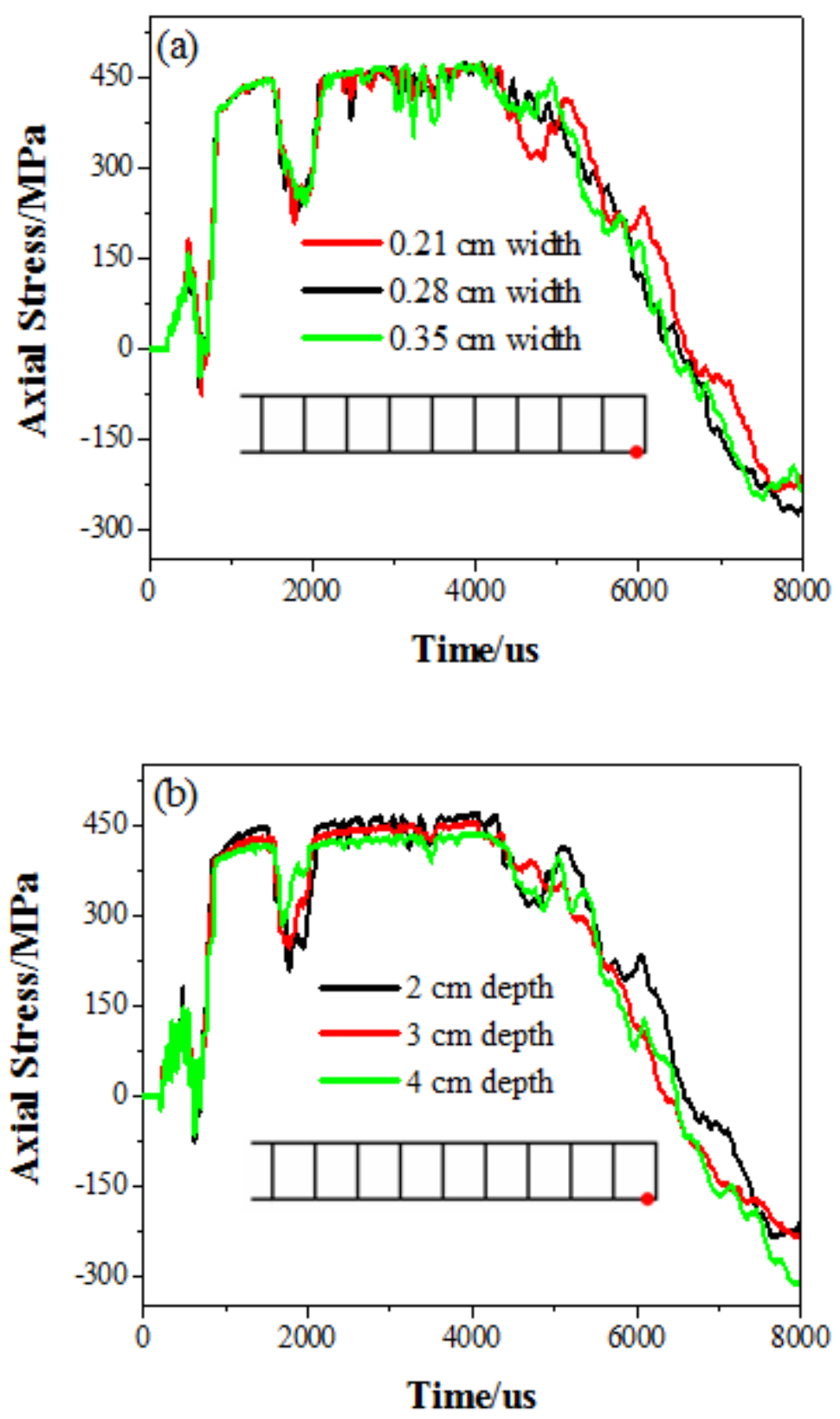

Fig. 15 


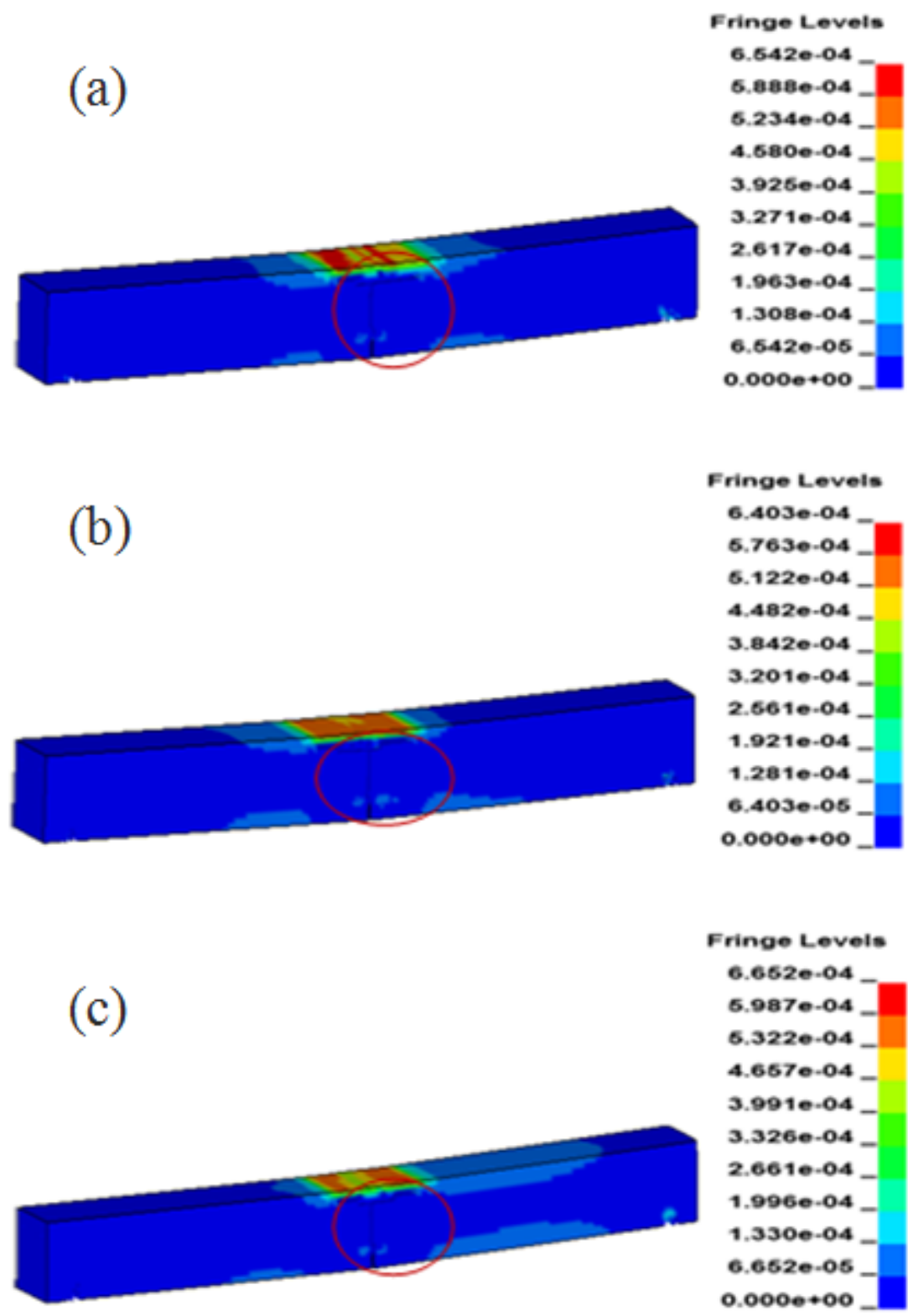

Fig. 16 

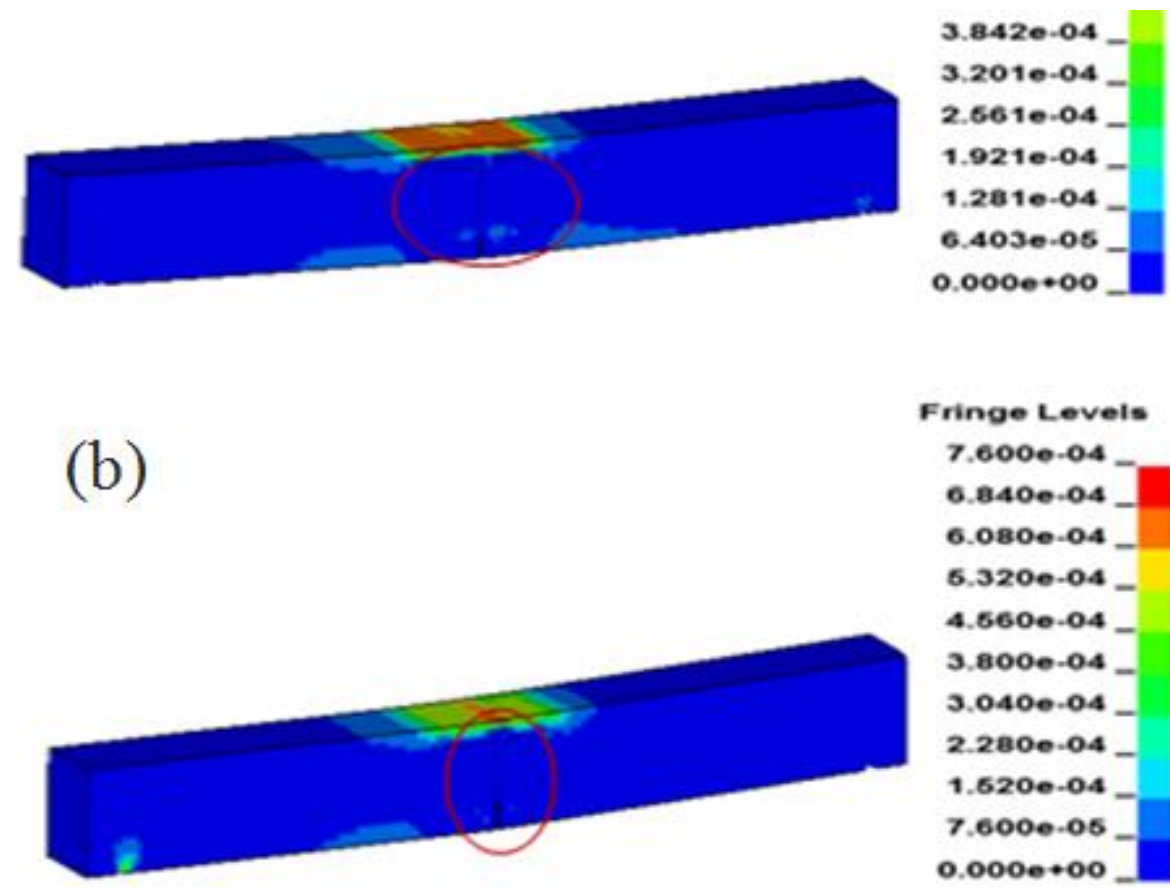

Fringe Levels

$7.6000-04$

6.840e.0.4

6.080e-04

6.320e-0.4

4.6600.04

3.800e-0.4

3.0.40e.04

2.2800 .04

1.6200 .04

7.6000 .06

0.000 e+00

(c)

Fringe Levets

6.7770 .04

6.100e-04

6.422e.04

4.744e.0.4

4.066e.04

3.3890 .04

2.7110 .04

2.033e.04

1.365e.04

6.7770 .06

0.000e+00

Fig. 17 

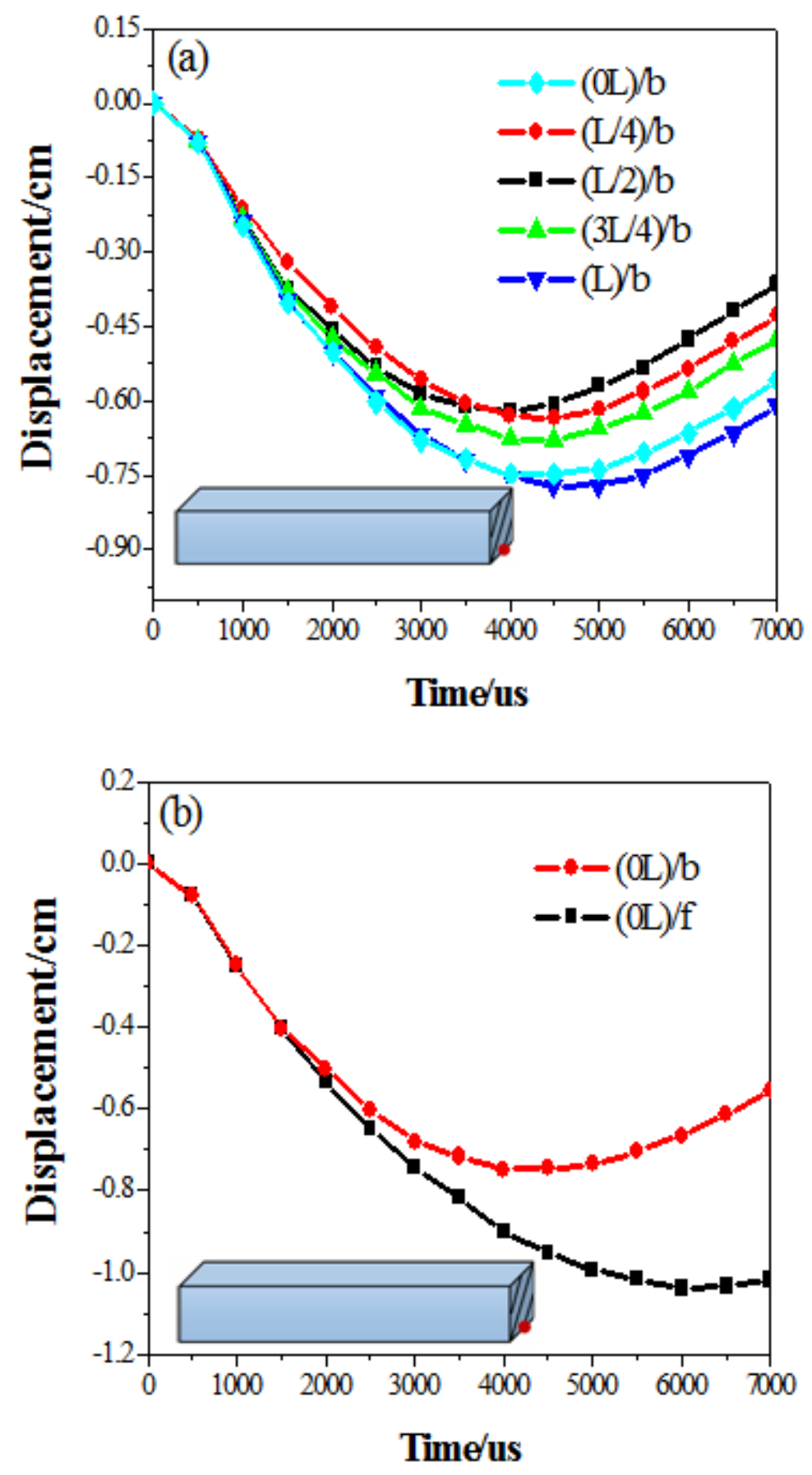

Fig. 18 


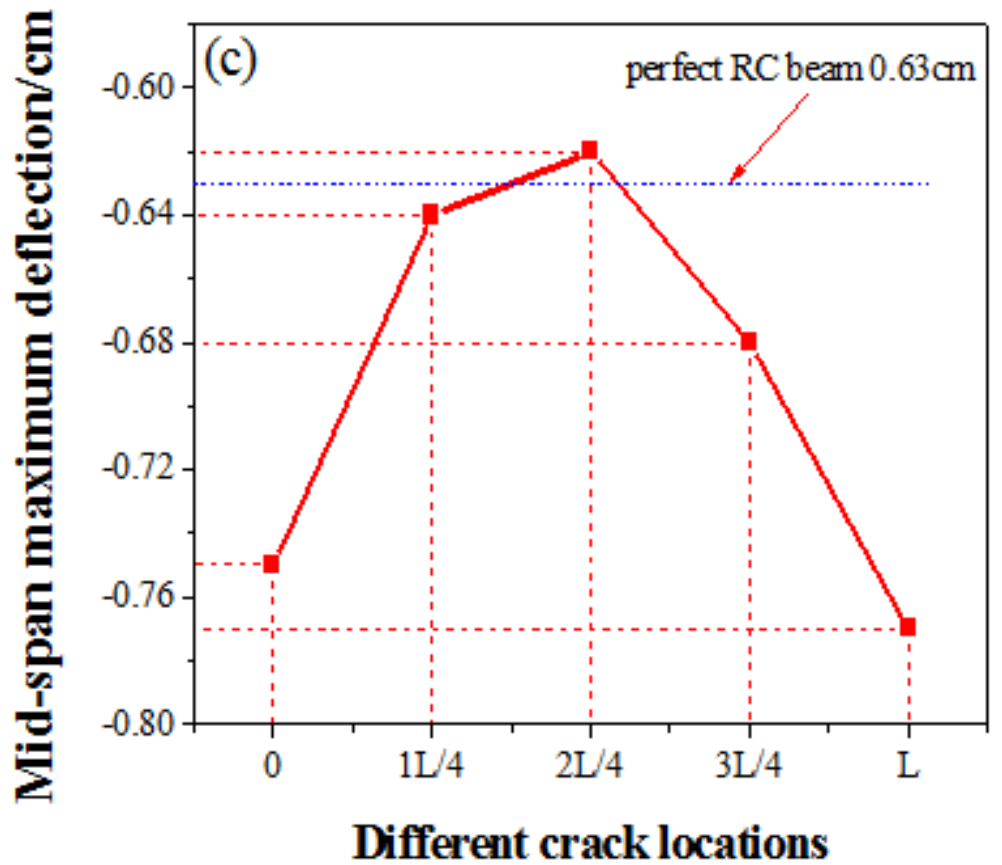

Fig. 19 

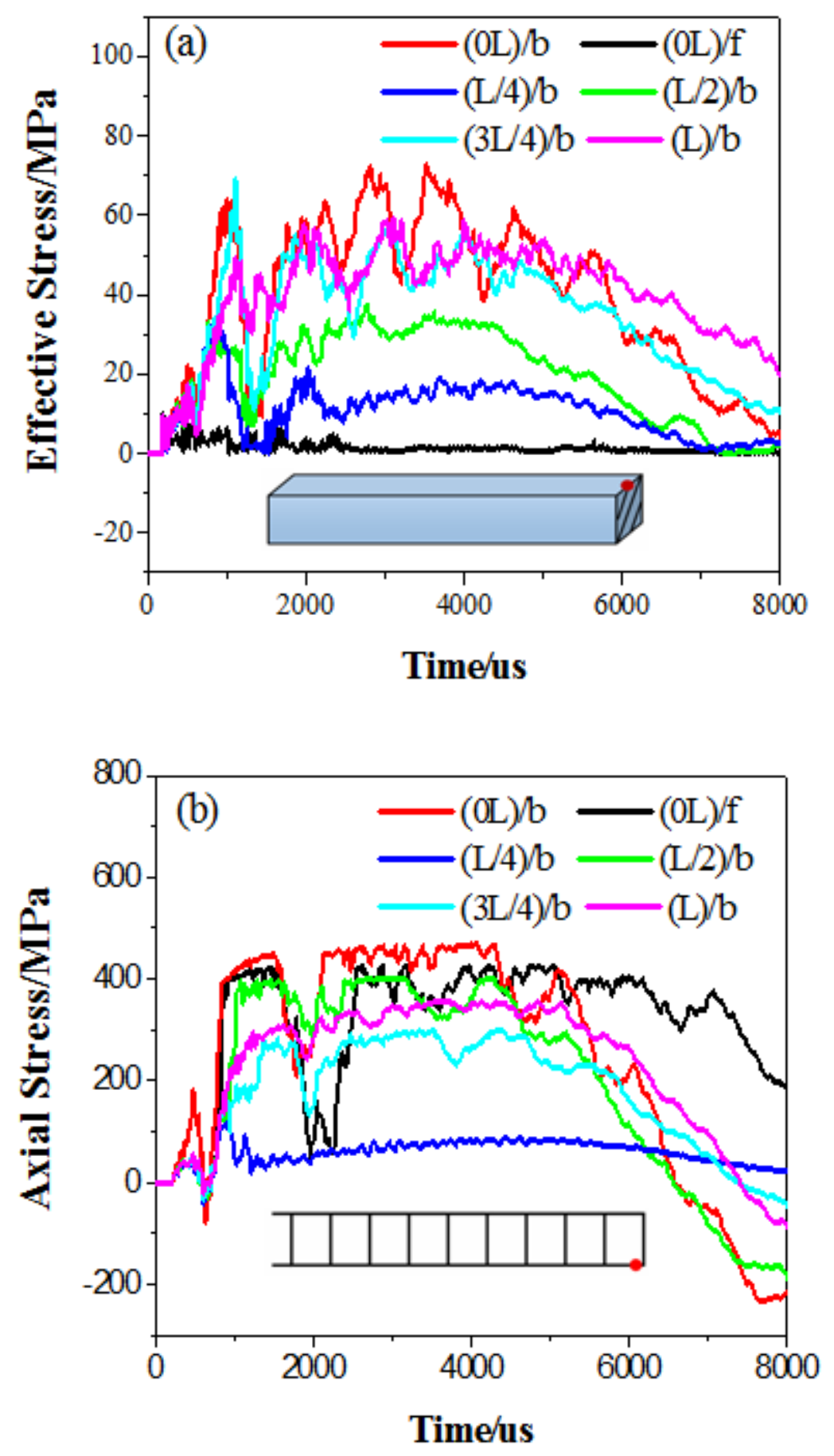

Fig. 20 

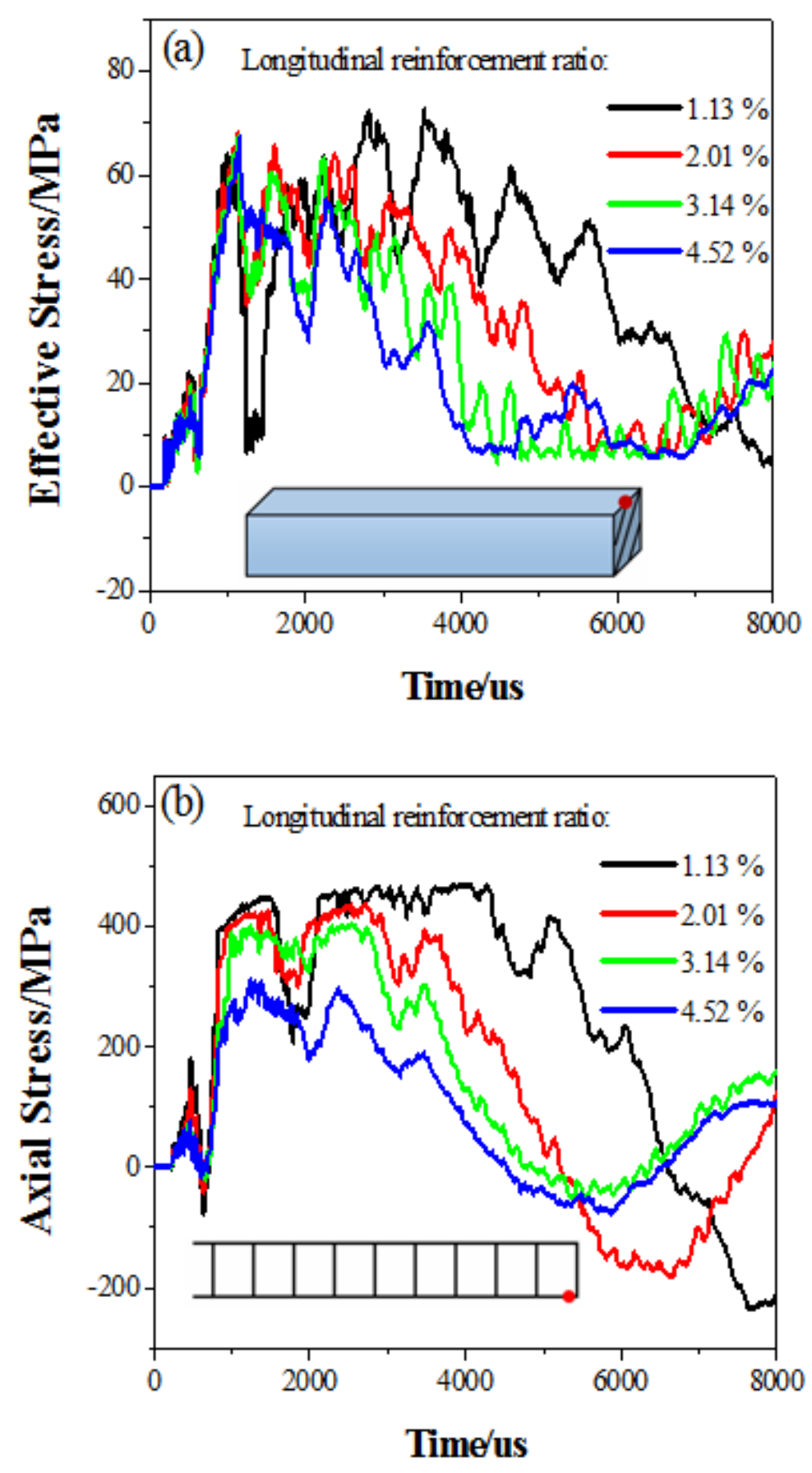

Fig. 21 


$$
==
$$




\section{Table Captions}

Table 1 Material parameters of ordinary concrete [33]

\begin{tabular}{cccc}
\hline Mass density, RO & $2440 \mathrm{~kg} \cdot \mathrm{m}^{-3}$ & Amount of plastic strain before fracture, EFMIN & 0.01 \\
Normalized cohesive strength, A & 0.79 & Crushing pressure, PC & $0.016 \mathrm{GPa}$ \\
Normalized pressure hardening, B & 1.6 & Crushing volumetric strain, UC & 0.001 \\
Pressure hardening exponent, N & 0.6 & Pressure constant, $\mathrm{K}_{1}$ & $85 \mathrm{GPa}$ \\
Strain rate coefficient, C & 0.007 & Pressure constant, $\mathrm{K}_{2}$ & $-171 \mathrm{GPa}$ \\
Quasi-static uniaxial compressive strength, FC & $0.040 \mathrm{GPa}$ [7] & Pressure constant, $\mathrm{K}_{3}$ & $208 \mathrm{GPa}$ \\
Normalized maximum strength, SFMAX & 7.0 & Locking pressure, PL & $0.80 \mathrm{GPa}$ \\
Damage constant, $\mathrm{D}_{1}$ & 0.004 & Locking volumetric strain, UL & 0.10 \\
Damage constant, $\mathrm{D}_{2}$ & 1.0 & Maximum tensile hydrostatic pressure, T & $0.004 \mathrm{GPa}$ \\
\hline
\end{tabular}

Table 2 Material parameters of steel reinforcement [37-38]

\begin{tabular}{cc}
\hline Mass density, RO & $7800 \mathrm{~kg} \cdot \mathrm{m}^{-3}$ \\
Young's modulus, E & $2.0 \times 10^{5} \mathrm{MPa}$ \\
Poisson's ratio, PR & 0.3 \\
Yield stress, SIGY & $395 \mathrm{MPa}[7]$ \\
Tangent modulus, ETAN & $2.0 \times 10^{3} \mathrm{MPa}$ \\
Hardening parameter, BETA & 0 \\
Strain rate parameter, SRC & 40 \\
Strain rate parameter, SRP & 5 \\
Failure strain for eroding elements, FS & 0.12 \\
\hline
\end{tabular}

Table 3 Influence of crack's presence under different detonating positions of TNT charges

\begin{tabular}{|c|c|c|c|c|c|c|c|}
\hline No. & $\begin{array}{c}\text { Crack } \\
\text { location/f or } \\
\text { b }\end{array}$ & $\begin{array}{l}\text { Crack depth } \\
\text { (cm) /width } \\
\text { (cm) }\end{array}$ & $\begin{array}{l}\text { TNT } \\
(\mathrm{g})\end{array}$ & $\begin{array}{c}\text { Detonating position of } \\
\text { TNT }\end{array}$ & $\begin{array}{c}\text { Explosive } \\
\text { distance }(\mathrm{cm})\end{array}$ & $\begin{array}{c}\text { Scaled } \\
\text { distance } \\
\left(\mathrm{m} / \mathrm{kg}^{1 / 3}\right)\end{array}$ & $\begin{array}{c}\text { Maximum } \\
\text { deflection } \mathrm{W}_{\max } \\
(\mathrm{cm})\end{array}$ \\
\hline 1 & No crack & - & 500 & $\begin{array}{l}\text { Above the mid-span } \\
\text { top of the beam }\end{array}$ & 50 & 0.63 & 0.63 \\
\hline 2 & No crack & - & 500 & $\begin{array}{c}\text { Above the } \\
\text { quarter-span top of the } \\
\text { beam }\end{array}$ & 50 & 0.63 & 0.49 \\
\hline 3 & $(0 \mathrm{~L}) / \mathrm{b}$ & $2 / 0.28$ & 500 & $\begin{array}{l}\text { Above the mid-span } \\
\text { top of the beam }\end{array}$ & 50 & 0.63 & 0.75 \\
\hline 4 & $(0 \mathrm{~L}) / \mathrm{b}$ & $2 / 0.28$ & 500 & $\begin{array}{c}\text { Above the } \\
\text { quarter-span top of the } \\
\text { beam }\end{array}$ & 50 & 0.63 & 0.61 \\
\hline
\end{tabular}

Note (same in the following tables): $\mathrm{f}$ or b: on the top or bottom surface of RC beam; L: half of the beam span. 
Table 4 Influence of the locations of the initial cracks

\begin{tabular}{|c|c|c|c|c|c|c|c|}
\hline No. & $\begin{array}{c}\text { Crack } \\
\text { location/f or } \\
b\end{array}$ & $\begin{array}{c}\text { Crack depth } \\
\text { (cm) /width } \\
\text { (cm) }\end{array}$ & $\begin{array}{l}\text { TNT } \\
(\mathrm{g})\end{array}$ & $\begin{array}{c}\text { Explosive } \\
\text { distance }(\mathrm{cm})\end{array}$ & $\begin{array}{c}\text { Scaled } \\
\text { distance } \\
\left(\mathrm{m} / \mathrm{kg}^{1 / 3}\right)\end{array}$ & Observations & $\begin{array}{c}\text { Maximum } \\
\text { deflection } \mathrm{W}_{\max } \\
(\mathrm{cm})\end{array}$ \\
\hline 1 & $(0 \mathrm{~L}) / \mathrm{b}$ & $2 / 0.28$ & 500 & 50 & 0.63 & Broken at cracked section & 0.75 \\
\hline 2 & $(0 \mathrm{~L}) / \mathrm{f}$ & $2 / 0.28$ & 500 & 50 & 0.63 & Broken at cracked section & 1.04 \\
\hline 3 & $(\mathrm{~L} / 4) / \mathrm{b}$ & $2 / 0.28$ & 500 & 50 & 0.63 & $\begin{array}{l}\text { Broken at cracked section and } \\
\text { near the mid-span of the beam }\end{array}$ & 0.64 \\
\hline 4 & $(\mathrm{~L} / 2) / \mathrm{b}$ & $2 / 0.28$ & 500 & 50 & 0.63 & $\begin{array}{l}\text { Broken at cracked section and } \\
\text { near the mid-span of the beam }\end{array}$ & 0.62 \\
\hline 5 & $(3 \mathrm{~L} / 4) / \mathrm{b}$ & $2 / 0.28$ & 500 & 50 & 0.63 & $\begin{array}{l}\text { Broken at cracked section and } \\
\text { near the mid-span of the beam }\end{array}$ & 0.68 \\
\hline 6 & $(\mathrm{~L}) / \mathrm{b}$ & $2 / 0.28$ & 500 & 50 & 0.63 & $\begin{array}{l}\text { Broken at cracked section and } \\
\text { near the mid-span of the beam }\end{array}$ & 0.77 \\
\hline
\end{tabular}

Table 5 Influence of longitudinal reinforcement ratio

\begin{tabular}{|c|c|c|c|c|c|c|c|c|c|}
\hline No. & $\begin{array}{l}\text { Longitudinal } \\
\text { reinforcement } \\
\text { diameter }\end{array}$ & $\begin{array}{l}\text { longitudinal } \\
\text { reinforcement } \\
\text { ratio }\end{array}$ & $\begin{array}{c}\text { Crack } \\
\text { location/ } \\
\text { f or b }\end{array}$ & $\begin{array}{c}\text { Crack depth } \\
(\mathrm{cm}) / \text { width } \\
(\mathrm{cm})\end{array}$ & $\begin{array}{l}\text { TNT } \\
(\mathrm{g})\end{array}$ & $\begin{array}{l}\text { Explosive } \\
\text { distance } \\
(\mathrm{cm})\end{array}$ & $\begin{array}{c}\text { Scaled } \\
\text { distance } \\
\left(\mathrm{m} / \mathrm{kg}^{1 / 3}\right)\end{array}$ & Observations & $\begin{array}{l}\text { Maximum } \\
\text { deflection } \\
\mathrm{W}_{\max }(\mathrm{cm})\end{array}$ \\
\hline 1 & $6 \mathrm{~mm}$ & $1.13 \%$ & $(0 \mathrm{~L}) / \mathrm{b}$ & $2 / 0.28$ & 500 & 50 & 0.63 & $\begin{array}{c}\text { Broken at cracked } \\
\text { section }\end{array}$ & 0.75 \\
\hline 2 & $8 \mathrm{~mm}$ & $2.01 \%$ & $(0 \mathrm{~L}) / \mathrm{b}$ & $2 / 0.28$ & 500 & 50 & 0.63 & $\begin{array}{c}\text { Broken at cracked } \\
\text { section }\end{array}$ & 0.51 \\
\hline 3 & $10 \mathrm{~mm}$ & $3.14 \%$ & $(0 \mathrm{~L}) / \mathrm{b}$ & $2 / 0.28$ & 500 & 50 & 0.63 & $\begin{array}{c}\text { Broken at cracked } \\
\text { section }\end{array}$ & 0.39 \\
\hline 4 & $12 \mathrm{~mm}$ & $4.52 \%$ & $(0 \mathrm{~L}) / \mathrm{b}$ & $2 / 0.28$ & 500 & 50 & 0.63 & $\begin{array}{l}\text { Broken at cracked } \\
\text { section and near } \\
\text { the mid-span of } \\
\text { the beam }\end{array}$ & 0.32 \\
\hline
\end{tabular}

